\title{
Conteúdos Ideológicos da Nova Direita no Município de São Paulo:
} análise de surveys ${ }^{1}$

\author{
Maria Teresa Gonzaga Alves
}

Mestre em Sociologia - USP

\begin{abstract}
Resumo
Este artigo apresenta algumas evidências de que os conteúdos ideológicos associados à agenda da nova direita encontram-se disseminados junto ao público da cidade de São Paulo. Esse fenômeno se inscreve na tendência mundial de renovação da direita observada nos países capitalistas avançados, desde meados dos anos 70, e no Brasil, a partir do final dos anos 80 . Na cidade de São Paulo, o sucesso eleitoral da direita parece estar associado a sua capacidade de se renovar e de apresentar seus interesses particulares como se fossem demandas sociais. Esta hipótese foi testada a partir de surveys realizados em 1993 e 1995. Os resultados da primeira pesquisa indicam que os conteúdos da direita mais programática são mais associados aos estratos sociais mais ricos que, em geral, apoiam os programas neoliberais e são antiesquerda; entre os setores mais pobres há maior afeição com os temas ligados à moralidade e ao autoritarismo, mas também ao estatismo.
\end{abstract}

Palavras-chave: voto de direita; eleições; nova direita; neoliberalismo; São Paulo.

\section{Abstract}

This article shows some evidences that the ideological content of the new right agenda is spread out amongst the public of the city of São Paulo. Such a particular phenomenon is further associated with a broader disposition, that is, the renewal of the right since the mid 1970s in advanced capitalist societies, and in Brazil at large since the late 1980s. The electoral success of the right seems to be associated to its capacity to renew itself and to present its own interests as though social demands. This hypothesis was tested in surveys conducted in the city of São Paulo in 1993 and 1995. The results of the first investigation indicate that the agenda of the more programmatic right is associated with the richer sectors of the society which, in general, support the neoliberal programme whilst being also anti-leftists. Amongst the poorer sectors however, there is more sensitivity towards topics related to morality and authoritarism, as well as statism.

Key words: right wing electorate; elections; new right; neoliberalism; São Paulo.

\footnotetext{
${ }^{1} \mathrm{O}$ presente artigo é uma versão de um dos capítulos da dissertação de mestrado apresentada à FFLCH da USP. Agradeço ao meu orientador, Antônio Flávio Pierucci, e às Professoras Maria Célia Paoli e Rachel Meneguello pelas valiosas críticas e observações feitas pela ocasião da defesa. Os erros que permanecem são, naturalmente, de exclusiva responsabilidade da Autora.
} 


\section{Introdução}

Desde meados dos anos 70 , vários países do mundo ocidental experimentaram uma notável revitalização da direita no espectro político partidário. Os governos de Margaret Thatcher, na Inglaterra, e de Ronald Reagan, nos Estados Unidos, iniciados em 1979 e 1980, respectivamente, são considerados os marcos iniciais desse fenômeno. Ao longo da década seguinte, vitórias de partidos conservadores foram registradas em outros países da Europa Ocidental e, após o colapso do comunismo na Europa Oriental e na União Soviética, de 1989 a 1991, reformas neoliberais varreram também o mundo póscomunista. Nos anos 90 , os partidos conservadores somaram mais vitórias do que derrotas em países que viveram anos sob governos social-democratas, como a França e a Espanha. Na América Latina, a onda neoliberal chegou a partir do final dos anos 80 , junto com os governos Alberto Fujimori, no Peru, Carlos Menem, na Argentina, Carlos Salinas, no México, e Fernando Collor, no Brasil (Anderson, 1995). Essa tendência sugere a existência de uma tangível sensibilidade por parte da sociedade aos argumentos defendidos por esta ideologia, pelo menos até onde os resultados eleitorais revelam o que as pessoas desejam.

A revitalização da direita não se manifesta apenas pelo êxito do programa neoliberal em diversas partes do mundo. Uma onda de conservadorismo social constitui a outra faceta da nova direita no mundo contemporâneo. Parece haver um paralelo entre a ofensiva neoliberal e uma simétrica barbarização da vida societária, com os problemas do desemprego, da exclusão social, das várias formas de preconceito (racial, cultural, sexual, religioso etc.) e da escalada da violência em grande parte do mundo capitalista. As soluções conservadoras são as que mais se beneficiam nesse cenário.

A partir de meados dos anos 90 , houve um reverso nessa tendência, com vitórias de partidos social-democratas nos países centrais da Europa, ${ }^{2}$ fechando um ciclo que marcou os anos 80 como a "era do conservadorismo" (Cueva,1989). No entanto, nada indica que a nova direita tenha perdido sua força. Em todo o mundo, as políticas de privatização e de desregulamentação estão na ordem do dia. A recente ascensão da extrema direita ao poder na Áustria surpreendeu a Europa e foi seguida por manifestações contrárias em vários países daquele continente.

\footnotetext{
${ }^{2}$ A volta dos social-democratas ao poder nos países da Europa começou na Itália, em 1996, com uma coalizão de centroesquerda liderada por Massimo D’Alema, do Partido Democrático da Esquerda (ex-comunista). Em 1997, foi a vez dos Partidos Trabalhista (Tony Blair) e Socialista (Leonel Jospin) que ganharam as eleições para os governos do Reino Unido e da França, respectivamente. No ano seguinte, os Socialistas venceram as eleições na Alemanha (Gerhart Schroeder). Em alguns países, porém, a volta da social-democracia ao poder se inscreve numa nova tendência conhecida como "Terceira Via" que, em linhas gerais, representa um movimento de modernização do centro. O sociólogo Anthony Giddens tem se notabilizado, nos últimos anos, pelas suas ligações com essa corrente, que ele define como uma política de esquerda do Novo Trabalhismo inglês para o século 21, e por suas afinidades com o governo de Tony Blair, o qual o autor tenta enquadrar neste esquema. Sobre isto, ver artigo publicado no jornal "Folha de São Paulo, de 21 de fevereiro de 1999.
} 
A nova direita, assim como a direita, é um fenômeno plural (Bobbio, 1995). O rótulo "nova direita" tem sido empregado genericamente para se referir a partidos políticos, políticas públicas, movimentos culturais e círculos de debates acadêmicos. Algumas das vertentes desse mosaico da direita renovada são La Nouvelle Droite - a nova direita francesa - (Taguieff, 1990 e 1993-94), The New Right - a nova direita norteamericana - (Hunter, 1991; Mouffe, 1981), The New Christian Right - a nova direita cristã nos Estados Unidos - (Hunter, op. cit.; Smith, 1992), o neoconservadorismo (Habermas, 1989; Giddens, 1994), o neoliberalismo (Anderson, op. cit.; Giddens, op. cit.) e a extrema direita (Ignazzi, op. cit.; Ignazi \& Ysmal, 1992; Mudde, 1995, Jackman \& Volpert, 1996). As fronteiras entre elas nem sempre são muito bem definidas, pois as vertentes da nova direita se inspiram umas nas outras, reagem umas sobre as outras, misturam-se, mas também se afastam. Em comum há a crítica ao modelo igualitário erigido no segundo pósguerra nas democracias liberais. De uma forma geral, as correntes da nova direita querem repensar e propor novos parâmetros para as sociedades capitalistas avançadas frente à crise do Estado de Bem-Estar, seja através da justificativa teórica do antiigualitarismo ou de propostas de cortes nas políticas de bem-estar social.

A transposição do debate internacional para o Brasil revela novas e grandes complexidades. Primeiro, porque aqui a nova direita é uma construção teórica, pois não há partidos políticos, grupos para a defesa de interesses específicos ou círculos acadêmicos que se auto-nomeiem como tal. Aliás, nem como de direita simplesmente, porque no Brasil os que se encontram à direita no espectro político geralmente se apresentam publicamente como liberais ou conservadores (Martins, 1987). Portanto, falar em nova direita no Brasil é antes se referir ao conteúdo programático de partidos políticos, ou à retórica e à forma de atuação política de alguns setores específicos da sociedade que se diferenciam dos paradigmas da "velha direita" (apesar de grande parte dos principais personagens da "nova direita" terem emergido do interior desta última) do que propriamente a um projeto institucionalmente estabelecido em termos de partidos políticos ou ainda a um modelo ideologicamente bem definido (Souza, 1992).

Assim entendida, a nova direita no Brasil é também um fenômeno plural, mas com fronteiras muito mais difusas. A sua delimitação se dá a partir da formação de novas clivagens político-eleitorais na Nova República. Porém, não ocorreu uma guinada repentina da velha direita em direção à nova direita. $\mathrm{Na}$ verdade, na transição de um regime ao outro houve uma continuidade das forças políticas conservadoras de direita ou centro-direita, assim como ocorreu em praticamente toda a história política do Brasil, inclusive em todos os governos na Nova República, com apenas um lapso no período imediatamente anterior ao golpe militar de 1964. A mudança mais significativa a partir da Nova República é que os setores conservadores se incorporaram mais do que nunca às instituições democráticas e se desvincularam progressivamente do passado autoritário (Mainwaring, et al., 2000). 
Atualmente, o neoliberalismo é a principal corrente da direita no país, porque a sua agenda de privatizações e desregulamentações se tornou hegemônica junto aos setores conservadores e se opõe à esquerda, defensora do estatismo (Mainwaring, et al, ibid.; Souza, op. cit.). Porém, nas análises sobre a questão brasileira é recorrente a ênfase ao caráter matizado da versão brasileira do neoliberalismo em que o liberalismo do laissez-faire coincide com o conservadorismo no campo social.

Nesse recorte se insere a linha de pesquisa sobre a direita no município de São Paulo, que também inspira este trabalho, com ênfase na trajetória do político Paulo Maluf, figura paradigmática da direita contemporânea no Brasil (Pierucci, 1989; Pierucci \& Lima, 1991 e 1992; Alves, 1999). Maluf é detentor de um perfil político que melhor representa o sentido de renovação da direita. Oriundo da base de apoio do regime militar, ele se tornou um dos políticos de maior empatia com a capital paulista. A virada de mesa de Maluf em relação ao seu passado associado ao período autoritário ocorreu com a comprovação de viabilidade eleitoral da esquerda nas eleições de 1988, com a vitória de Luiza Erundina, do Partido dos Trabalhadores (PT). A partir daí e nas eleições seguintes que concorreu, além de se verificar um crescimento contínuo de sua base eleitoral, esta também ascendeu na escala social. Antes de 1988, quando Maluf concorreu ao governo do estado em 1986, as suas votações mais expressivas ocorreram nos bairros predominantemente de classe média-baixa, setores mais afeitos ao discurso personalista, moralista e autoritário que deram o tom de sua campanha (assim como foi no ano anterior na campanha do prefeito eleito Jânio Quadros). Nas campanhas seguintes, as prioridades passaram a ser a eficiência administrativa, o perfil empreendedor em sintonia com o espírito neoliberal que começava a surgir no país. Maluf soube capitanear a insatisfação da elite conservadora da capital com o crescimento da esquerda, dando início a uma trajetória vitoriosa. Mantendo-se fiel e coerentemente filiado ao mesmo agrupamento político-partidário desde o regime militar, $^{3}$ aos poucos dissimulou a sua imagem vinculada ao regime autoritário e conquistou as classes mais ricas, assumindo o posto de principal liderança anti-esquerda na cidade, logo, de direita (Lima, 1995).

O objetivo deste artigo é apresentar algumas evidências de que os conteúdos associados à agenda da nova direita encontram-se disseminados junto ao público da cidade de São Paulo e que a população é sensível a este debate. A partir de pesquisas de opinião pública do tipo survey realizadas na cidade, procuraremos demonstrar que o debate ideológico no contexto da nova direita travado no nível das elites do país pode ter sido um fator relevante nas escolhas eleitorais, sobretudo a partir das eleições presidenciais de 1989, e também encontra-se presente entre os valores da população em geral em função do recrudescimento deste debate a partir dos anos 90 .

\footnotetext{
${ }^{3} \mathrm{O}$ atual partido de Paulo Maluf, PPB (Partido Progressista Brasileiro), é resultado da fusão do PPR (Partido Progressista Reformador), sucessor da ARENA/PDS (Aliança Renovadora Nacional / Partido Democrático Social), com vários pequenos partidos conservadores.
} 


\section{Medindo Posição Ideológica no Contínuo Esquerda-direita}

André Singer (1998), em sua tese de doutorado demonstrou a existência de conteúdos significativos associados ao posicionamento na escala esquerda-direita do eleitorado brasileiro. O autor investigou a relação entre identificação ideológica e direção do voto nas eleições presidenciais de 1989 e 1994 com base em pesquisas de opinião e encontrou forte associação entre uma e outra variável. Por identificação ideológica entende-se a adesão a uma posição no contínuo esquerda-direita, ou liberal-conservador, como medidas de orientação política do eleitor. Este autor pôde inferir que, mesmo que de forma difusa ou cognitivamente desestruturada, a identificação ideológica se destacou como um forte preditor do comportamento eleitoral e se mostrou mais poderosa do que outras variáveis clássicas e igualmente importantes nesse tipo de estudo, como nível socioeconômico e identificação partidária.

Quanto aos conteúdos ideológicos associados à dimensão esquerda-direita, Singer concluiu que no Brasil o igualitarismo, ao contrário do que ocorre no contexto europeu, não parece ser um divisor entre esquerda e direita, porque as opiniões convergiam para uma valorização quase unânime do igualitarismo, pelo menos enquanto um ideal. $\mathrm{O}$ estatismo se mostrou associado positivamente com posições extremas tanto à direita quanto à esquerda e negativamente com as posições de centro; o autoritarismo se mostrou positivamente associado à direita. $\mathrm{O}$ autor também observou que o público que converge para o centro é mais inclinado para as posições da direita do que para as da esquerda. Os dados analisados pelo autor sugerem que a auto-localização na escala está associada a um sistema de crenças em que a principal clivagem é o desejo de reforçar a autoridade repressiva do Estado, à direita, e a contestação dessa autoridade, à esquerda, remetendo para a clássica separação entre os que defendem a ordem e os que desejam transformá-la, com o centro, obviamente, na posição intermediária.

Este tipo de estudo é interessante porque procura traduzir em conteúdos substantivos associados à realidade uma representação simbólica imaginária que é o contínuo ideológico esquerda-direita. Isso é um grande desafio, pois esses conteúdos variam muito em função dos contextos e dos conflitos políticos de cada época ou local. Mas este esforço analítico permite ampliar muito o poder explicativo da simples autolocalização na escala esquerda-direita e ajuda a entender muito dos comportamentos e atitudes dos públicos pesquisados. ${ }^{4}$

\footnotetext{
${ }^{4}$ Fuchs \& Klingemann (1990) analisaram a eficiência da autolocalização na escala esquerda-direita em países europeus e nos Estados Unidos e concluíram que este tipo de classificação tem um considerável efeito no comportamento e nas atitudes políticas do público. Segundo as palavras dos autores: "This research indicates that so-called ideological self-identificationmensured as self-placement on a left-right or liberal-conservative scale - has considerable effects on political behavior and political attitudes. Thus, ideological self-identification has considerable explanatory power, even though many respondentes interpret or understand ideological terms at a non-ideological level and only a minority of citizens actively uses ideological terms to classify and evaluate political issues."(pp.204). "Thus, we postulate that the meaning of the left-right schema is defined by the basic conflits of the specific social system. [...]...individual left-right schemata can be seen as incomplete reflections of the coletive shema of left and right."'(p. 207).
} 
O nosso propósito aqui é mais modesto. Pretendemos explorar a aceitação de alguns conteúdos associados às posições no espectro esquerda-direita, especialmente os temas relacionados à nova direita. A análise foi direcionada para a cidade de São Paulo, pois o nosso foco de interesse é o fenômeno da preferência por candidatos de direita no município.

Diante do cenário único da capital paulista, havia indícios de que poderíamos encontrar algumas tendências diferenciadas em relação ao quadro nacional analisado por Singer (ibid.). Desde o início da Nova República, a capital paulista tem se destacado pelo progressivo crescimento da direita nas eleições majoritárias, mesmo quando não vencedora, ou do centro, mormente quando este está coligado com aquela. ${ }^{5}$ Além disso, a pesquisa qualitativa conduzida por Pierucci (1987) junto às bases sociais do voto conservador na cidade de São Paulo detectou o antiigualitarismo como a principal característica desses eleitores, apesar de não se manifestarem sobre o neoliberalismo. Ao contrário, os ativistas da direita em meados da década de 80 , nos primórdios da Nova República, eram a favor do Estado, entendido no âmbito dos serviços públicos. A continuidade dos estudos sobre as bases sociais do voto conservador revelou mudanças significativas no perfil do voto de direita na cidade com a incorporação contínua de parcelas de eleitores mais bem situados na escala social (Pierucci \& Lima, 1991; Novais, 1996b). Esse aspecto nos pareceu sugerir que os conteúdos associados à direita também poderiam mudar, assumir novos sentidos, se renovar em relação ao "conservadorismo popular" detectado anteriormente.

O resultado das eleições presidenciais de 1989 descortinou este comportamento eleitoral diferenciado do paulistano em relação às outras grandes cidades do país. Enquanto no cômputo nacional venceram no primeiro turno Fernando Collor de Mello, candidato de direita, e Luís Inácio Lula da Silva, da esquerda, na capital paulista os vencedores foram Mário Covas, de perfil centro-esquerda, e Paulo Maluf, de direita. Ou seja, se dependesse somente do eleitorado paulistano, a história recente do país poderia ser bem outra. No segundo turno, os votos do candidato vitorioso na capital, Mário Covas, não se transferiram integralmente para Lula, o que seria esperado dentro da lógica dos campos ideológicos. Collor venceu na maior cidade do Brasil, obtendo ali a sua melhor votação entre as dez capitais de maior eleitorado do país, revertendo a tendência ascendente do PT de Lula, mais bem votado quanto maior fosse o eleitorado do município. ${ }^{6}$ Assim, se no cenário nacional, os resultados evidenciaram um certo equilíbrio

\footnotetext{
${ }^{5}$ Esta é uma tendência notável principalmente quando contrastada com a tradição esquerdista que marcou a capital paulista no período pré-abertura. Os estudos desenvolvidos desde 1974 pela equipe de pesquisadores do IDESP mostram que o conjunto do eleitorado da capital possuía uma perfil antimilitar, votando maciçamente nos candidatos do MDB e foi assim até o fim do regime militar (Lamounier \& Cardoso,1975; Lamounier \& Muszynski,1983; Meneguello \& Martins Alves, 1986; Sadek, 1986; Muszynski,1989).

${ }^{6}$ Entre as dez capitais de estado de maior eleitorado do país. Fernando Collor venceu no segundo turno somente em São Paulo (48,9\% dos votos), Curitiba e Belém (42,7\% e 47,5\%, respectivamente). Nas outras grandes capitais (Rio de Janeiro, Belo Horizonte, Salvador, Brasília, Recife, Porto Alegre e Fortaleza), a sua votação oscilou entre $20 \%$ e cerca de $30 \%$. Fonte: TSE, citado por Moisés (1990).
} 
entre a direita e a esquerda, ${ }^{7}$ na cidade de São Paulo o mesmo não ocorreu, pois, não obstante a vitória do centro no primeiro turno, as forças da direita foram proporcionalmente muito mais bem votadas do que as da esquerda ou mesmo as do centro. ${ }^{8}$ Além disso, a votação expressiva do candidato Paulo Maluf naquele ano confirmou o bom desempenho da direita em áreas mais ricas da cidade, fenômeno já detectado no ano anterior no contexto da eleição municipal e que se repetiu no ano seguinte na eleição estadual (Pierucci \& Lima, 1991).

\section{Metodologia: dados de surveys}

Neste trabalho, analisamos dois conjuntos de dados de opinião pública disponíveis no Centro de Estudos de Opinião Pública da Universidade Estadual de Campinas (CESOP): uma pesquisa nacional realizada em 1993, parte do Projeto "Cultura política e consolidação da democracia no Brasil", ${ }^{9}$ na qual os dados referentes à cidade de São Paulo somam 195 entrevistas, e uma pesquisa do Instituto Datafolha realizada em 1995 para avaliação do governo estadual, que aborda alguns temas debatidos no Congresso Nacional no contexto da reforma constitucional, constituída de 463 entrevistas. $^{10}$

A pesquisa "Cultura Política" foi ao campo seis meses após o impeachment do presidente eleito em 1989, Fernando Collor de Mello, durante o governo do presidente Itamar Franco. Escolhemos analisar esses dados porque a investigação reúne uma ampla gama de variáveis sobre valores do eleitorado, algumas delas relacionadas mais diretamente aos conteúdos geralmente associados à agenda da nova direita, como opiniões sobre o igualitarismo, o estatismo, o autoritarismo e alguns itens sobre questões morais. Além disso, foi possível relacionar as opiniões dos entrevistados com variáveis ideológicas, das quais escolhemos o voto nas eleições de 1989, no primeiro e no segundo turnos, e a auto-localização ideológica no contínuo esquerda-direita.

A segunda pesquisa, de 1995, foi realizada aos três meses do primeiro mandato do presidente Fernando Henrique Cardoso, e abordou questões da agenda de debates do Congresso Nacional na época. Os questionamentos da pesquisa foram objetivamente

\footnotetext{
${ }^{7}$ Na eleição presidencial de 1989, Singer (1998) observou que, considerando a soma das votações de todos os candidatos da direita e da esquerda, houve um equilíbrio das forças em disputa. Além disso, o segundo turno foi decidido por uma margem mínima entre o candidato da direita, Fernando Collor, e o da esquerda, Lula, o que confirmou a tendência esboçada na fase anterior.

${ }^{8}$ Na cidade de São Paulo, entre os cinco mais bem votados no primeiro turno das eleições de 1989, o primeiro colocado era de centro (Mário Covas, com cerca 31,9\%); três de direita (Maluf, com 23,4\%; Collor, com 17\%, e Afif, com 3,9\%) e um de esquerda (Lula, com 15,2\%). Fonte: Pierucci \& Lima (1991).

${ }^{9}$ O projeto "Cultura política e consolidação da democracia no Brasil" foi realizado pelo consórcio entre o Instituto Datafolha, o Centro de Estudos de Cultura Contemporânea (Cedec) e a Universidade de São Paulo (USP), coordenado pelos professores José Álvaro Moisés e José Augusto Guilhon Albuquerque, do Departamento de Ciência Política da USP. Os dados analisados foram obtidos no Centro de Estudos de Opinião Pública (CESOP) da Universidade Estadual de Campinas (Unicamp). O número de registro desta pesquisa no CESOP é: DAT/BR93.MAR-00322.

${ }^{10}$ Número de registro da pesquisa no CESOP é: DAT/BR95.JUN-00432.
} 
inseridos naquele contexto, com temas que se relacionavam mais diretamente à agenda neoliberal e à moralidade privada, porém abordados de forma diferente da pesquisa de 1993, daí porque não podemos diretamente compará-las.

Naturalmente, os dados de que dispomos não cobrem toda a gama de conteúdos relevantes, pois foram coletados a partir de outros pressupostos. Apesar desses limites, foi possível resgatar concepções e percepções sobre alguns conteúdos que nos interessam e relacioná-las com atitudes e características do público.

Os dados de opinião analisados são apresentados de forma descritiva, através das freqüências de ocorrências das diversas categorias observadas e em tabelas de contingência ou tabelas cruzadas, que apresentam as relações entre as variáveis destacadas. Em cada uma das tabelas são apresentados os valores do qui-quadrado, que testa a hipótese de independência entre as variáveis em questão, e o seu nível de significância. Convencionalmente, somente valores de significância inferiores a 0,05 permitem rejeitar a hipótese de independência entre as variáveis (ou ausência de associação significativa). Porém, como as amostras disponíveis são reduzidas, muitas vezes isso comprometeu os testes de associação. Assim, algumas vezes as tabelas que serão apresentadas a seguir não atingem índices de associação muito fortes, mas seus resultados, na maioria das vezes, são bastante coerentes com as hipóteses sugeridas e por isso mostramos seus resultados mesmo com valores de significância acima do nível recomendável. ${ }^{11}$ No corpo das tabelas também são exibidos os valores dos resíduos ajustados para cada célula, que informa quando a freqüência observada é significativamente diferente da esperada numa situação de não-associação. Adotando um critério convencional, são significativos (ao nível de significância de 0,05) valores superiores a 1,96, em número absoluto. Porém, algumas vezes iremos destacar resultados com nível de significância menor, quando nos parecer que os valores da tabela seguem a tendência esperada (ver nota acima).

\footnotetext{
${ }^{11}$ Apresentamos tabelas cruzadas com nível de significância variando de $\mathrm{p}<0,01$ a $\mathrm{p}<0,20$, neste último caso, apenas quando nos parecer que a distribuição de freqüências da tabela sugere a tendência esperada, mas ficou compremetida pelo número reduzido de dados disponíveis. Segundo um manual de estatística que consultamos para definir estes parâmetros, o nível de significância "é sempre relativo e não constitui um problema do estatístico, senão do especialista na área em que determinada pesquisa esteja sendo feita." (Levin, Jack, Estatística aplicada a ciências humanas, São Paulo: Harper \& Row do Brasil, 1977 pp. 136.)
} 


\section{Análise dos Dados de Surveys}

\section{Dados de 1993}

\subsection{Posição ideológica no contínuo esquerda-direita}

$\mathrm{Na}$ pesquisa de opinião de 1993, procuramos investigar quais os conteúdos ideológicos estavam associados à visão de mundo do público da cidade de São Paulo, considerando a autoclassificação ideológica dos entrevistados e a direção do voto nas eleições de $1989 .{ }^{12}$ Mas antes de proceder a análise, verificamos se os dados disponíveis apontavam para uma relação coerente entre estas duas variáveis; ou seja, estávamos interessados em saber se os entrevistados que se autoclassificaram como de direita votaram nos candidatos da direita, da mesma maneira, se os candidatos da esquerda foram mais votados por pessoas que se assumiam como de esquerda.

Podemos observar na Tabela $1^{13}$ uma nítida associação entre a direção do voto dos entrevistados ${ }^{14}$ e a autolocalização na escala esquerda-direita, ${ }^{15}$ ou seja, mostrando a coerência da escolha dos candidatos com a posição ideológica do eleitor. O voto em Fernando Collor foi maior entre os eleitores que se auto-localizaram à direita $(55,6 \%)$ e ao centro-direita $(51,2 \%)$. O desempenho de Luís Inácio Lula da Silva piorou no sentido esquerda-direita da escala, com o máximo percentual entre os eleitores à esquerda $(57,1 \%)$ e o mínimo entre os à direita $(11,1 \%)$.

O candidato vencedor no primeiro turno na capital, Mário Covas, se saiu muito bem entre os eleitores ao centro-esquerda $(50,0 \%)$. Paulo Maluf se sobressaiu entre os eleitores autolocalizados ao centro $(24,1 \%)$. Este último caso, a princípio, foge do padrão esperado. Porém, observamos que o desempenho de Maluf foi melhor entre os

\footnotetext{
${ }^{12}$ Aqui uma observação importante. As informações sobre o voto no primeiro e no segundo turno de 1989, coletadas em 1993, divergiram muito do resultado oficial. Em estudos pós-eleitorais, isso é um fato normal, principalmente neste caso, em que a pesquisa foi realizada mais de dois anos após o pleito. Novos eleitores que não votaram em 1989 somaram-se à base amostral e outros certamente saíram, além de serem registrados muitos casos de não resposta, provavelmente devido ao efeito do desatrelamento das candidaturas perdedoras em sondagens pós-eleitorais (Singer, 1993), o que fez inchar acima do real a freqüência observada para os candidatos mais bem votados no pleito nacional, divergindo o resultado válido para a cidade. No entanto, as questões sobre o voto nas eleições de 1989 foram incluídas na pesquisa não como parâmetros de voto, mas sim como variáveis de estratificação, assim como a renda familiar, a escolaridade, a identificação partidária, a religião, etc. Lidos desta forma (e assim que deve ser, pois não há sentido em pesquisar parâmetros de voto em relação a um evento do passado), os resultados das nossas análises procuraram apenas refletir as opiniões dos subgrupos de entrevistados, dentro das limitações estatísticas impostas pela amostra reduzida, como já assinalamos anteriormente.

${ }^{13}$ Estamos apresentado nesta e nas tabelas seguintes apenas os casos de respostas válidas, ou seja, excluímos os casos de "não respostas" e "não sabe", que foram somados aos casos perdidos (missing cases) a fim de simplificar as tabelas e evitar dispersão nas respostas. Consideramos o procedimento válido porque não estamos interessados em fazer inferências sobre o voto.

${ }^{14}$ Pergunta: [Para quem votou para presidente da República, em 1989] "Em que candidato você votou no $1^{\circ}$ turno? E no $2^{\circ}$ turno, você votou no Collor ou no Lula?"

${ }^{15}$ A pergunta sobre a autolocalização na escala esquerda-direita foi a seguinte: "Para muita gente as atitudes políticas são de esquerda ou de direita. Aqui tem uma escala que vai da esquerda à direita. Pensando nas suas próprias atitudes políticas, onde você se situaria?" [É apresentado uma escala com dez pontos, minimo à esquerda (1) e máximo à direita (10)]. Para facilitar a análise as dez categorias foram agrupadas em pares, formando cinco categorias, assim nomeadas por nós: posições 1 e 2 : esquerda; posições 3 e 4: centro-esquerda; posições 5 e 6: centro; posições 7 e 8: centro-direita; posições 9 e 10: direita.
} 
entrevistados à direita $(18,6 \%$ ao centro-direita e $16,7 \%$ à direita) do que entre os à esquerda ( $14,3 \%$ à esquerda e $7,1 \%$ ao centro-esquerda), uma indicação sobre o sentido em que pendia o eleitorado de Maluf, o que foi comprovado pelo comportamento desses eleitores no segundo turno (como veremos na próxima tabela).

TABELA 1

Voto na eleição de 1989 por autolocalização na escala esquerda-direita

\begin{tabular}{|c|c|c|c|c|c|c|}
\hline \multirow[b]{2}{*}{ Eleição de 1989 (\%) } & \multicolumn{5}{|c|}{ Autolocalização na escala esquerda-direita (\%) } & \multirow[b]{2}{*}{ Total } \\
\hline & Esquerda & $\begin{array}{c}\text { Centro- } \\
\text { esquerda }\end{array}$ & Centro & $\begin{array}{c}\text { Centro- } \\
\text { direita }\end{array}$ & Direita & \\
\hline Voto no $1^{\circ}$ turno: & \multicolumn{5}{|c|}{$\left({ }^{*}\right)$} & \\
\hline Collor & $\begin{array}{c}28,6 \\
-, 9 \\
\end{array}$ & $\begin{array}{l}14,3 \\
-2,1 \\
\end{array}$ & $\begin{array}{l}31,0 \\
-1,1 \\
\end{array}$ & $\begin{array}{c}51,2 \\
1,9 \\
\end{array}$ & $\begin{array}{c}55,6 \\
1,5 \\
\end{array}$ & 38,1 \\
\hline Lula & $\begin{array}{c}57,1 \\
3,3 \\
\end{array}$ & $\begin{array}{c}28,6 \\
, 5 \\
\end{array}$ & $\begin{array}{c}24,1 \\
, 2 \\
\end{array}$ & $\begin{array}{l}14,0 \\
-1,7 \\
\end{array}$ & $\begin{array}{l}11,1 \\
-1,3 \\
\end{array}$ & 23,2 \\
\hline Mário Covas & $-\overline{-}$ & $\begin{array}{c}50,0 \\
3,1\end{array}$ & $\begin{array}{c}20,7 \\
, 2 \\
\end{array}$ & $\begin{array}{c}16,3 \\
-, 7 \\
\end{array}$ & $\begin{array}{c}16,7 \\
-, 3 \\
\end{array}$ & 19,8 \\
\hline Paulo Maluf & $\begin{array}{l}14,3 \\
-, 4 \\
\end{array}$ & $\begin{array}{r}7,1 \\
-1,1 \\
\end{array}$ & $\begin{array}{c}24,1 \\
1,0 \\
\end{array}$ & $\begin{array}{c}18,6 \\
, 2 \\
\end{array}$ & $\begin{array}{c}16,7 \\
-, 1 \\
\end{array}$ & 19,0 \\
\hline \multirow[t]{2}{*}{ Total \% (N) } & $\begin{array}{c}100,0 \\
(14)\end{array}$ & $\begin{array}{c}100,0 \\
(14)\end{array}$ & $\begin{array}{c}100,0 \\
(29)\end{array}$ & $\begin{array}{c}100,0 \\
(43)\end{array}$ & $\begin{array}{c}100,0 \\
(18) \\
\end{array}$ & $\begin{array}{l}100,0 \\
(125) \\
\end{array}$ \\
\hline & \multicolumn{5}{|c|}{ Qui-quadrado observado: 27,205} & \\
\hline Voto no $1^{\circ}$ turno: & \multicolumn{5}{|c|}{$\left({ }^{*}\right)$} & \\
\hline Direita & $\begin{array}{l}40,0 \\
-1,3 \\
\end{array}$ & $\begin{array}{l}26,3 \\
-2,8 \\
\end{array}$ & $\begin{array}{c}53,1 \\
-, 4 \\
\end{array}$ & $\begin{array}{c}69,6 \\
2,3 \\
\end{array}$ & $\begin{array}{c}72,2 \\
1,5 \\
\end{array}$ & 55,7 \\
\hline Centro & $\begin{array}{c}, 0 \\
-2,1 \\
\end{array}$ & $\begin{array}{c}47,4 \\
3,1 \\
\end{array}$ & $\begin{array}{c}21,9 \\
, 2 \\
\end{array}$ & $\begin{array}{c}17,4 \\
-, 7 \\
\end{array}$ & $\begin{array}{l}16,7 \\
-, 5 \\
\end{array}$ & 21,0 \\
\hline Esquerda & $\begin{array}{c}60,0 \\
3,6 \\
\end{array}$ & $\begin{array}{c}26,3 \\
, 4\end{array}$ & $\begin{array}{c}25,0 \\
, 3\end{array}$ & $\begin{array}{l}13,0 \\
-2,0 \\
\end{array}$ & $\begin{array}{l}11,1 \\
-1,3 \\
\end{array}$ & 23,3 \\
\hline Total \% $(\mathrm{N})$ & $\begin{array}{c}100,0 \\
(15)\end{array}$ & $\begin{array}{l}100,0 \\
(19)\end{array}$ & $\begin{array}{c}100,0 \\
(32)\end{array}$ & $\begin{array}{c}100,0 \\
(46)\end{array}$ & $\begin{array}{c}100,0 \\
(18)\end{array}$ & $\begin{array}{l}100,0 \\
(137) \\
\end{array}$ \\
\hline & \multicolumn{5}{|c|}{ Qui-quadrado observado: 28,191} & \\
\hline Voto no $2^{\circ}$ turno: & \multicolumn{5}{|c|}{$\left({ }^{*}\right)$} & \\
\hline Collor & $\begin{array}{l}31,3 \\
-2,9 \\
\end{array}$ & $\begin{array}{l}35,0 \\
-2,9 \\
\end{array}$ & $\begin{array}{c}74,3 \\
1,5 \\
\end{array}$ & $\begin{array}{c}72,0 \\
1,5 \\
\end{array}$ & $\begin{array}{c}83,3 \\
1,8 \\
\end{array}$ & 62,9 \\
\hline Lula & $\begin{array}{c}68,8 \\
2,9 \\
\end{array}$ & $\begin{array}{c}65,0 \\
2,9 \\
\end{array}$ & $\begin{array}{l}25,7 \\
-1,5 \\
\end{array}$ & $\begin{array}{l}28,0 \\
-1,5 \\
\end{array}$ & $\begin{array}{l}16,7 \\
-1,8 \\
\end{array}$ & 37,1 \\
\hline Total \% (N) & $\begin{array}{c}100,0 \\
(16) \\
\end{array}$ & $\begin{array}{c}100,0 \\
(20)\end{array}$ & $\begin{array}{c}100,0 \\
(35) \\
\end{array}$ & $\begin{array}{c}100,0 \\
(50) \\
\end{array}$ & $\begin{array}{c}100,0 \\
(18) \\
\end{array}$ & $\begin{array}{l}100,0 \\
(143) \\
\end{array}$ \\
\hline
\end{tabular}

Qui-Quadrado significativo para o nível de $\mathrm{P}<0,01\left(^{*}\right)$

Fonte: Banco de Dados CESOP / Unicamp 
Essas associações ficaram mais significativas com o agrupamento dos candidatos do primeiro turno (os quatro citados e os outros menos votados) em função do posicionamento ideológico de seus respectivos partidos. ${ }^{16}$ Notamos que o bloco dos candidatos de direita melhorou muito o seu desempenho junto aos entrevistados que se auto-localizaram na posição mais à direita $(72,2 \%)$ e centro-direita $(69,6 \%)$. O bloco de esquerda repetiu a tendência verificada em relação ao candidato Lula, com o máximo entre os de esquerda $(60,0 \%)$ e mínimo no lado oposto à direita $(11,1 \%)$. A mesma constatação é válida para o centro, que repetiu o padrão verificado para Mário Covas, com uma freqüência maior entre os de centro-esquerda $(47,4 \%)$. O interessante aqui é notar, que para o bloco de esquerda e de centro, houve poucas alterações em relação aos valores dos candidatos mais importantes (Lula e Covas, respectivamente) considerados isoladamente, porque os demais candidatos do bloco tiveram votações insignificantes. Já no conjunto dos candidatos da direita, este tipo de tratamento dos dados acentuou a coerência em relação à autolocalização na direita, porque o bloco conta com pelo menos dois candidatos com votações expressivas (Collor e Maluf).

A última parte da tabela, referente ao segundo turno das eleições, é claramente polarizada. A votação de Collor aumentou a partir da posição central em direção à direita com índices de $74,3 \%$ ao centro, $72,0 \%$ ao centro-direita e $83,3 \%$ à direita, enquanto os melhores resultados de Lula foram registrados no sentido inverso: $65,0 \%$ ao centroesquerda e $68,8 \%$ à esquerda.

A Tabela 2 indica como se deu a distribuição dos votos do primeiro turno para os dois candidatos do segundo turno. Observamos que a candidatura Collor foi reforçada pelos eleitores de Maluf $(70,0 \%)$ e principalmente pela categoria dos "outros candidatos" (75,0\%), e Lula recebeu mais votos dos eleitores de Mário Covas (63,2\%). Organizando os dados por grupos ideológicos, mais uma vez ficou nítida a polarização no segundo turno, pois a maioria dos eleitores que votou nos candidatos de direita ou de esquerda repetiu o voto no segundo turno (no percentual estão incluídos os eleitores que repetiram o voto nos mesmos candidatos nos primeiro e segundo turno, ou seja, em Collor e em Lula). Também é possível constatar que o centro (soma dos votos para o PSDB, de Mário Covas, com o PMDB, de Ulisses Guimarães) foi o grande fiel da balança, porque diluiu o

\footnotetext{
${ }^{16}$ Para a formação dos três grupos ideológicos, foi considerado a soma de respostas para todos os candidatos citados de acordo com uma classificação ideológica simplificada dos mesmos, a saber: candidatos de direita (Aureliano Chaves, do PFL, Guilherme Afif, do PL, Paulo Maluf, do PDS, Fernando Collor, do PRN, Ronaldo Caiado, do PSD, e Affonso Camargo, do PTB) de centro (Mário Covas, do PSDB, e Ulisses Guimarães, do PMDB) e Esquerda (Lula, do PT, Leonel Brizola, do PDT, e Roberto Freire, do PCB). Baseado em Lamounier (1989). Na classificação de Lamounier, o PSDB é classificado como centro-esquerda e o PMDB de centro-direita. Na nossa, baseamo-nos em Mainwaring, et al. (op. cit.) que consideram os dois partidos apenas como centro. Apesar do PMDB assim como o PSDB tenham adquirido um perfil mais conservador ao longo da Nova República, como afirmam estes autores, classificá-los como partidos conservadores seria ampliar demais o conceito de conservadorismo. Finalmente, ficaram fora do esquema os candidatos menos votados, que foram classificados no questionário aplicado na categoria "outras respostas", e não temos como recuperar a informação básica.
} 
peso da posição centro-esquerda do PSDB, vitorioso no primeiro turno, e reforçou tanto a candidatura Lula (um pouco mais) quanto a de Fernando Collor.

TABELA 2

Voto no $2^{\circ}$ turno da eleição de 1989 por voto no $1^{\circ}$ turno

\begin{tabular}{|c|c|c|c|c|c|c|c|c|c|}
\hline \multirow{3}{*}{$\begin{array}{c}\text { Voto } \\
\text { no } 2^{\circ} \\
\text { turno } \\
(\%)\end{array}$} & \multicolumn{5}{|c|}{ Voto no $1^{\circ}$ turno (\%) } & \multicolumn{3}{|c|}{$\begin{array}{l}\text { Voto no } 1^{\circ} \text { turno por classificação } \\
\text { ideológica dos candidatos }(\%)\end{array}$} & \multirow[t]{3}{*}{ Total } \\
\hline & Collor & Lula & Covas & Maluf & Outros & Direita & Centro & Esquerda & \\
\hline & \multicolumn{5}{|c|}{$\left({ }^{*}\right)$} & \multicolumn{3}{|c|}{$\left({ }^{*}\right)$} & \\
\hline Collor & $\begin{array}{c}97,9 \\
7,0\end{array}$ & $\begin{array}{l}3,4 \\
-7,1\end{array}$ & $\begin{array}{l}36,8 \\
-2,2\end{array}$ & $\begin{array}{c}70,0 \\
1,1\end{array}$ & $\begin{array}{c}75,0 \\
, 9\end{array}$ & $\begin{array}{c}88,7 \\
7,4\end{array}$ & $\begin{array}{l}43,5 \\
-1,8\end{array}$ & $\begin{array}{l}6,7 \\
-6,9\end{array}$ & 62,9 \\
\hline Lula & $\begin{array}{r}2,1 \\
-7,0 \\
\end{array}$ & $\begin{array}{c}96,6 \\
7,1 \\
\end{array}$ & $\begin{array}{l}63,2 \\
2 ., 2\end{array}$ & $\begin{array}{l}30,0 \\
-1,1\end{array}$ & $\begin{array}{l}25,0 \\
-, 9\end{array}$ & $\begin{array}{l}11,3 \\
-7,4 \\
\end{array}$ & $\begin{array}{c}56,5 \\
1,8 \\
\end{array}$ & $\begin{array}{c}93,3 \\
6,9 \\
\end{array}$ & 37,1 \\
\hline \multirow[t]{2}{*}{$\begin{array}{l}\text { Total \% } \\
(\mathrm{N})\end{array}$} & $\begin{array}{c}100,0 \\
(47)\end{array}$ & $\begin{array}{c}100,0 \\
(29)\end{array}$ & $\begin{array}{c}100,0 \\
(19) \\
\end{array}$ & $\begin{array}{c}100,0 \\
(20) \\
\end{array}$ & $\begin{array}{c}100,0 \\
(8)\end{array}$ & $\begin{array}{c}100,0 \\
(71)\end{array}$ & $\begin{array}{c}100,0 \\
(23) \\
\end{array}$ & $\begin{array}{l}100,0 \\
(30)\end{array}$ & $\begin{array}{l}100,0 \\
(143) \\
\end{array}$ \\
\hline & \multicolumn{5}{|c|}{ Qui-quadrado observado: 72,659} & \multicolumn{3}{|c|}{ Qui-quadrado observado: 62,841} & \\
\hline
\end{tabular}

$\left.{ }^{*}\right)$ Qui-quadrado significativo ao nível de $\mathrm{P}<0,01$

Fonte: Banco de Dados CESOP / Unicamp

Investigamos também como se deu a distribuição destes eleitores em função de algumas variáveis socioeconômicas. Já sabíamos, a partir dos estudos de geografia eleitoral no município de São Paulo, que os candidatos Mário Covas e Paulo Maluf receberam tanto mais votos quanto mais rica fosse a área da cidade e que Fernando Collor e Lula, ao contrário, foram mais bem votados nas regiões mais periféricas e mal nas áreas centrais mais bem aquinhoadas. ${ }^{17}$ Isso sugeria um outro eixo na disputa na capital opondo o centro à periferia sendo que, dentro de cada um desses pólos, havia uma disputa interna entre candidatos com perfis muito distintos. $\grave{A}$ falta de dados sobre distribuição geográfica do voto, utilizamos as variáveis escolaridade e renda familiar para inferir sobre as bases sociais do voto. Podemos dizer que encontramos tendências que, de certa forma, vão ao encontro das informações prévias e contribuem para reforçar a validade dos nossos dados.

Observamos na Tabela 3 que o desempenho de Fernando Collor caminhou no sentido inverso ao incremento da escolaridade e da renda familiar: atingiu o máximo de $100,0 \%$ entre os entrevistados analfabetos e $54,5 \%$ na primeira faixa de renda de até 2 s.m. (salário mínimo) e, no extremo oposto, obteve 16,0\% entre os entrevistados com curso superior e $23,8 \%$ entre os de renda familiar de mais de 20 s.m.. Neste recorte, o

\footnotetext{
${ }^{17}$ Pierucci \& Lima (1991) Tabela 7, página 24.
} 
candidato que teve um desempenho oposto ao de Collor não foi Lula, como se observou na análise anterior, mas Mário Covas, que melhorou o seu resultado no mesmo sentido positivo da escolaridade e da renda familiar: $40,0 \%$ na categoria de entrevistados com escolaridade de nível superior e $23,8 \%$ na faixa de renda entre 10 a 20 s.m., decrescendo até os índices de $8 \%$ no nível de primeiro grau (não há ocorrência na faixa analfabeto) e $8,8 \%$ entre os entrevistados com até 2 s.m.. Lula obteve mais votos entre os entrevistados com escolaridade e renda familiar intermediárias: $33,3 \%$ na faixa de escolaridade média ( $2^{\circ}$ grau) e $36,0 \%$ entre aqueles com renda familiar de 5 a 10 s.m.. Paulo Maluf se saiu melhor entre os entrevistados com escolaridade mínima de $2^{\circ} \mathrm{grau}$ $(22,2 \%)$, mas também entre aqueles com nível superior (20,0\%). Quanto à renda familiar, é interessante observar que Maluf obteve melhores resultados no topo e na base da pirâmide social: $33,3 \%$ junto aos entrevistados com renda familiar de mais de 20 s.m. e $27,3 \%$ entre os mais pobres.

Estes dados sugerem que a polarização centro-periferia estava, de certa forma, reproduzida na distribuição dos votos entre Fernando Collor e Mário Covas, de acordo com os indicadores de escolaridade e renda familiar. Os índices dos outros dois candidatos também reforçam essa tendência, apesar de estarem diluídos entre os dois pólos: Paulo Maluf, como esperado, pendeu um pouco mais para o topo da pirâmide social, onde disputou votos com Mário Covas (apesar de marcar presença também na base, na faixa de renda mais baixa), e Lula se consolidou no ponto mais central do eixo e piorou nos extremos.

Nos dados relativos ao segundo turno, chamamos a atenção para a manutenção do mesmo padrão de Lula (melhor nas faixas intermediárias de escolaridade e renda familiar) e, principalmente, para a reversão da tendência decrescente de Fernando Collor no topo da pirâmide. Na disputa final, Collor subiu na faixa de renda mais alta (acima de 20 s.m.), indicando que as bases sociais do voto de Collor foram incrementadas com os votos dos eleitores mais ricos. 
TABELA 3

Voto no $1^{\circ}$ e $2^{\circ}$ turno da eleição de 1989 por escolaridade e renda familiar

\begin{tabular}{|c|c|c|c|c|c|c|c|c|c|c|}
\hline \multirow{2}{*}{$\begin{array}{l}\text { Voto eleição de } \\
1989(\%)\end{array}$} & \multicolumn{4}{|c|}{ Escolaridade (\%) } & \multicolumn{5}{|c|}{ Renda Familiar (\%) } & \multirow{3}{*}{ Total } \\
\hline & $\begin{array}{c}\text { Analfa- } \\
\text { beto }\end{array}$ & $\begin{array}{c}1^{\circ} \\
\text { grau }\end{array}$ & $\begin{array}{c}2^{\circ} \\
\text { grau }\end{array}$ & $\begin{array}{l}\text { Supe- } \\
\text { rior }\end{array}$ & $\begin{array}{l}\text { Até } 2 \\
\text { S.M. }\end{array}$ & $\begin{array}{l}+2 \text { a } 5 \\
\text { S.M. }\end{array}$ & $\begin{array}{c}+5 a \\
10 \text { S.M. }\end{array}$ & $\begin{array}{c}+10 a \\
20 \text { S.M. }\end{array}$ & $\begin{array}{l}+20 \\
\text { S.M. }\end{array}$ & \\
\hline Voto no $1^{\circ}$ turno: & \multicolumn{4}{|c|}{$\left({ }^{*}\right)$} & \multicolumn{5}{|c|}{$\left({ }^{* \star * *}\right)$} & \\
\hline Collor & $\begin{array}{c}100,0 \\
2,6\end{array}$ & $\begin{array}{c}56,1 \\
3,7 \\
\end{array}$ & $\begin{array}{l}19,4 \\
-2,8 \\
\end{array}$ & $\begin{array}{l}16,0 \\
-2,6 \\
\end{array}$ & $\begin{array}{c}54,5 \\
1,2 \\
\end{array}$ & $\begin{array}{c}53,8 \\
1,9 \\
\end{array}$ & $\begin{array}{l}28,0 \\
-1,2 \\
\end{array}$ & $\begin{array}{l}26,7 \\
-1,5 \\
\end{array}$ & $\begin{array}{l}23,8 \\
-1,5 \\
\end{array}$ & 38,1 \\
\hline Lula & $\begin{array}{c}, 0 \\
-1,1\end{array}$ & $\begin{array}{l}17,5 \\
-1,3\end{array}$ & $\begin{array}{c}33,3 \\
1,8\end{array}$ & $\begin{array}{c}24,0 \\
, 1\end{array}$ & $\begin{array}{c}9,1 \\
-1,2\end{array}$ & $\begin{array}{c}23,1 \\
, 0\end{array}$ & $\begin{array}{c}36,0 \\
1,7\end{array}$ & $\begin{array}{c}26,7 \\
, 5\end{array}$ & $\begin{array}{l}19,0 \\
-, 5\end{array}$ & 23,2 \\
\hline Mário Covas & $\begin{array}{c}0 \\
-1,0\end{array}$ & $\begin{array}{c}8,8 \\
-2,8 \\
\end{array}$ & $\begin{array}{c}25,0 \\
1,0 \\
\end{array}$ & $\begin{array}{c}40,0 \\
2,9 \\
\end{array}$ & $\begin{array}{l}9,1 \\
-, 9 \\
\end{array}$ & $\begin{array}{l}11,5 \\
-1,2 \\
\end{array}$ & $\begin{array}{c}24,0 \\
, 6\end{array}$ & $\begin{array}{c}26,7 \\
1,1 \\
\end{array}$ & $\begin{array}{c}23,8 \\
, 5 \\
\end{array}$ & 19,8 \\
\hline Paulo Maluf & $\begin{array}{c}, 0 \\
-1,0 \\
\end{array}$ & $\begin{array}{l}17,5 \\
-, 3 \\
\end{array}$ & $\begin{array}{c}22,2 \\
, 6 \\
\end{array}$ & $\begin{array}{c}20,0 \\
, 2\end{array}$ & $\begin{array}{c}27,3 \\
, 7\end{array}$ & $\begin{array}{l}11,5 \\
-1,1 \\
\end{array}$ & $\begin{array}{l}12,0 \\
-1,0 \\
\end{array}$ & $\begin{array}{c}20,0 \\
, 2 \\
\end{array}$ & $\begin{array}{c}33,3 \\
1,8 \\
\end{array}$ & 19,0 \\
\hline \multirow[t]{2}{*}{ Total \% (N) } & $\begin{array}{c}100,0 \\
(4)\end{array}$ & $\begin{array}{c}100,0 \\
(57) \\
\end{array}$ & $\begin{array}{c}100,0 \\
(36) \\
\end{array}$ & $\begin{array}{c}100,0 \\
(25) \\
\end{array}$ & $\begin{array}{c}100,0 \\
(11)\end{array}$ & $\begin{array}{c}100,0 \\
(26)\end{array}$ & $\begin{array}{c}100,0 \\
(25) \\
\end{array}$ & $\begin{array}{c}100,0 \\
(30)\end{array}$ & $\begin{array}{c}100,0 \\
(21) \\
\end{array}$ & $\begin{array}{l}100,0 \\
(125) \\
\end{array}$ \\
\hline & \multicolumn{4}{|c|}{ Qui-quadrado observado: 29,597} & \multicolumn{5}{|c|}{ Qui-quadrado observado: 20,180} & \\
\hline Voto no $1^{\circ}$ turno: & \multicolumn{4}{|c|}{$\left({ }^{* *}\right)$} & \multicolumn{5}{|c|}{$\left({ }^{* * * *}\right)$} & \\
\hline Direita & $\begin{array}{c}100,0 \\
1,8 \\
\end{array}$ & $\begin{array}{c}70,0 \\
2,9 \\
\end{array}$ & $\begin{array}{l}43,2 \\
-1,8 \\
\end{array}$ & $\begin{array}{l}39,4 \\
-2,2 \\
\end{array}$ & $\begin{array}{l}83,3 \\
2,0 \\
\end{array}$ & $\begin{array}{c}58,6 \\
, 4 \\
\end{array}$ & $\begin{array}{l}39,3 \\
-2,0 \\
\end{array}$ & $\begin{array}{l}46,7 \\
-1,1 \\
\end{array}$ & $\begin{array}{c}57,7 \\
, 2 \\
\end{array}$ & 55,7 \\
\hline Centro & $\begin{array}{c}, 0 \\
-1,0 \\
\end{array}$ & $\begin{array}{l}11,7 \\
-2,4 \\
\end{array}$ & $\begin{array}{c}24,3 \\
, 6 \\
\end{array}$ & $\begin{array}{c}36,4 \\
2,5 \\
\end{array}$ & $\begin{array}{l}8,3 \\
-1,1 \\
\end{array}$ & $\begin{array}{l}17,2 \\
-, 6 \\
\end{array}$ & $\begin{array}{c}21,4 \\
, 1 \\
\end{array}$ & $\begin{array}{c}26,7 \\
, 9 \\
\end{array}$ & $\begin{array}{c}26,9 \\
, 8 \\
\end{array}$ & 21,0 \\
\hline Esquerda & $\begin{array}{c}, 0 \\
-1,1\end{array}$ & $\begin{array}{l}18,3 \\
-1,2 \\
\end{array}$ & $\begin{array}{c}32,4 \\
1,6 \\
\end{array}$ & $\begin{array}{c}24,2 \\
, 2 \\
\end{array}$ & $\begin{array}{c}8,3 \\
-1,3 \\
\end{array}$ & $\begin{array}{c}24,1 \\
, 1\end{array}$ & $\begin{array}{c}39,3 \\
2,3 \\
\end{array}$ & $\begin{array}{c}26,7 \\
, 5 \\
\end{array}$ & $\begin{array}{l}15,4 \\
-1,1 \\
\end{array}$ & 23,3 \\
\hline \multirow[t]{2}{*}{ Total \% (N) } & $\begin{array}{c}100,0 \\
(4) \\
\end{array}$ & $\begin{array}{c}100,0 \\
(60)\end{array}$ & $\begin{array}{c}100,0 \\
(37) \\
\end{array}$ & $\begin{array}{c}100,0 \\
(33)\end{array}$ & $\begin{array}{c}100,0 \\
(12)\end{array}$ & $\begin{array}{c}100,0 \\
(29)\end{array}$ & $\begin{array}{c}100,0 \\
(28)\end{array}$ & $\begin{array}{c}100,0 \\
(30)\end{array}$ & $\begin{array}{c}100,0 \\
(26) \\
\end{array}$ & $\begin{array}{l}100,0 \\
(137) \\
\end{array}$ \\
\hline & \multicolumn{4}{|c|}{ Qui-quadrado observado: 16,378} & \multicolumn{5}{|c|}{ Qui-quadrado observado: 14,176} & \\
\hline Voto no $2^{\circ}$ turno: & \multicolumn{4}{|c|}{$\left(*^{*}\right)$} & \multicolumn{5}{|c|}{$\left({ }^{* * *}\right)$} & \\
\hline Collor & $\begin{array}{c}100,0 \\
1,6\end{array}$ & $\begin{array}{c}75,0 \\
2,9 \\
\end{array}$ & $\begin{array}{l}47,5 \\
-2,3 \\
\end{array}$ & $\begin{array}{l}50,0 \\
-1,6 \\
\end{array}$ & $\begin{array}{c}83,3 \\
1,5\end{array}$ & $\begin{array}{c}75,0 \\
1,6 \\
\end{array}$ & $\begin{array}{c}56,3 \\
-, 9\end{array}$ & $\begin{array}{l}45,2 \\
-2,3 \\
\end{array}$ & $\begin{array}{c}64,0 \\
, 1 \\
\end{array}$ & 62,9 \\
\hline Lula & $\begin{array}{c}0 \\
-1,6 \\
\end{array}$ & $\begin{array}{l}25,0 \\
-2,9 \\
\end{array}$ & $\begin{array}{c}52,5 \\
2,3 \\
\end{array}$ & $\begin{array}{c}50,0 \\
1,6 \\
\end{array}$ & $\begin{array}{l}16,7 \\
-1,5 \\
\end{array}$ & $\begin{array}{l}25,0 \\
-1,6 \\
\end{array}$ & $\begin{array}{c}43,8 \\
, 9 \\
\end{array}$ & $\begin{array}{c}54,8 \\
2,3 \\
\end{array}$ & $\begin{array}{c}36,0 \\
-, 1 \\
\end{array}$ & 37,1 \\
\hline \multirow[t]{2}{*}{ Total \% (N) } & $\begin{array}{c}100,0 \\
(4)\end{array}$ & $\begin{array}{c}100,0 \\
(68)\end{array}$ & $\begin{array}{c}100,0 \\
(40)\end{array}$ & $\begin{array}{c}100,0 \\
(30)\end{array}$ & $\begin{array}{c}100,0 \\
(12)\end{array}$ & $\begin{array}{c}100,0 \\
(32)\end{array}$ & $\begin{array}{c}100,0 \\
(32)\end{array}$ & $\begin{array}{c}100,0 \\
(31)\end{array}$ & $\begin{array}{c}100,0 \\
(25)\end{array}$ & $\begin{array}{l}100,0 \\
(143)\end{array}$ \\
\hline & \multicolumn{4}{|c|}{ Qui-quadrado observado: 12,796} & \multicolumn{5}{|c|}{ Qui-quadrado observado: 9,829 } & \\
\hline
\end{tabular}

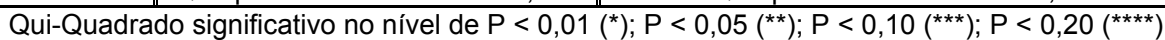

Fonte: Banco de Dados CESOP / Unicamp 
Finalmente, verificamos como a auto-localização na escala esquerda-direita variou em função da escolaridade e da renda familiar dos entrevistados. Segundo as análises de Singer (1998), a partir dos mesmos dados aqui utilizados, mas considerando a amostra nacional, ${ }^{18}$ "no Brasil, o eleitorado à direita é predominante pobre (a renda é mais baixa à direita do que à esquerda e mais baixa nos extremos do que no centro...)"(p. 153). No entanto, em função da votação mais expressiva do bloco dos candidatos de direita na cidade de São Paulo e em relação ao registrado no conjunto do eleitorado das grandes cidades do país, tínhamos a hipótese de que poderíamos encontrar um perfil diferenciado do observado, especialmente no pólo à direita. Além disso, foi na capital paulista que Paulo Maluf registrou a sua maior votação e ele se saiu melhor entre os eleitores mais ricos.

Os dados apresentados na Tabela 4 são frágeis para sustentar totalmente a nossa hipótese, porém não deixam de sinalizar tendências coerentes nessa direção. Lendo a Tabela de baixo para cima, os percentuais mostram que os entrevistados que se auto-localizaram nas posições mais extremas à direita tinham predominantemente escolaridade mais baixa $\left(25,0 \%\right.$ de analfabetos e $17,6 \%$ com até $01^{\circ}$ grau $)$ e renda familiar um grau acima da faixa mínima $(25,0 \%$ entre 2 a 5 s.m. e $14,6 \%$ entre 5 a 10 s.m.). Este perfil sugere um público de classe média-baixa, parecido com as bases sociais do eleitorado de Jânio Quadros, em 1985, e de Paulo Maluf, em 1986, encontradas nas pesquisas de Pierucci (1989) sobre o voto conservador na cidade de São Paulo. Na faixa logo acima, a autolocalização na posição de centro-direita repetiu o padrão da anterior em relação à escolaridade $\left(47,1 \%\right.$ com escolaridade até o $1^{\circ}$ grau $)$, mas nas categorias de renda familiar as freqüências maiores foram observadas nas duas faixas inferiores, caiu na faixa central e em seguida ensaiou um incremento nas duas faixas superiores. $O$ padrão de distribuição dos entrevistados autolocalizados ao centro seguiu o padrão esperado: escolaridade média $(35,8 \%)$ e superior $(34,1 \%)$ e renda familiar mais alta (37,8\%, mais de 10 a 20 s.m. e 35,3\%, mais de 20 s.m.). A autolocalização à esquerda foi associada às faixas intermediárias de escolaridade $\left(20,8 \%, 2^{\circ}\right.$ grau $)$ e renda familiar $(24,4 \%$, mais de 5 a 10 s.m.) e decaiu nos extremos, mais em direção às faixas de renda familiar mais altas e escolaridade superior do que ao contrário. Ou seja, se não podemos encontrar uma associação mais forte nas camadas mais ricas com a direita, no mínimo encontramos um desatrelamento destes estratos em relação à esquerda.

\footnotetext{
18 Além disso, na análise de André Singer, os pontos do contínuo esquerda-direita não foram agrupados em pares como fizemos aqui, e ele observou as variações na escolaridade e na renda familiar em função da autolocalização na escala esquerda-direita, porque o seu estudo investigou a relevância desta variável nos processos políticos analisados em sua pesquisa. Aqui, estamos tratando os dados de outra forma, considerando a autolocalização como uma variável dependente e procuramos inferir como a autolocalização na escala difere em função da escolaridade e da renda familiar do entrevistado.
} 
TABELA 4

Autolocalização na escala esquerda-direita por escolaridade e renda familiar

\begin{tabular}{|c|c|c|c|c|c|c|c|c|c|c|}
\hline \multirow{3}{*}{$\begin{array}{l}\text { Auto- } \\
\text { localização } \\
\text { (\%) }\end{array}$} & \multicolumn{4}{|c|}{$\begin{array}{c}\text { Escolaridade } \\
\%\end{array}$} & \multicolumn{5}{|c|}{$\begin{array}{c}\text { Renda Familiar } \\
\% \\
\end{array}$} & \multirow{3}{*}{ Total } \\
\hline & $\begin{array}{c}\text { Analfa- } \\
\text { beto }\end{array}$ & $1^{\circ}$ grau & $2^{\circ}$ grau & $\begin{array}{c}\text { Superi- } \\
\text { or }\end{array}$ & $\begin{array}{l}\text { Até } 2 \\
\text { S.M. }\end{array}$ & $\begin{array}{c}+2 \text { a } 5 \\
\text { S.M. }\end{array}$ & $\begin{array}{c}+5 \text { a } \\
10 \text { S.M. }\end{array}$ & $\begin{array}{c}+10 \mathrm{a} \\
20 \text { S.M. }\end{array}$ & $\begin{array}{l}+20 \\
\text { S.M. }\end{array}$ & \\
\hline & \multicolumn{4}{|c|}{$\left({ }^{*}\right)$} & \multicolumn{5}{|c|}{$\left({ }^{* *}\right)$} & \\
\hline Esquerda & $\begin{array}{r}0 \\
-, 7\end{array}$ & $\begin{array}{c}8,2 \\
-1,1 \\
\end{array}$ & $\begin{array}{c}20,8 \\
2,7\end{array}$ & $\begin{array}{r}4,9 \\
-1,4 \\
\end{array}$ & $\begin{array}{l}5,6 \\
-, 8\end{array}$ & $\begin{array}{l}10,0 \\
-, 2\end{array}$ & $\begin{array}{c}24,4 \\
3,1\end{array}$ & $\begin{array}{c}10,8 \\
, 0\end{array}$ & $\begin{array}{r}2,9 \\
-1,7 \\
\end{array}$ & 11,0 \\
\hline $\begin{array}{l}\text { Centro- } \\
\text { esquerda }\end{array}$ & $\begin{array}{c}25,0 \\
, 5\end{array}$ & $\begin{array}{l}12,9 \\
-1,2\end{array}$ & $\begin{array}{r}9,4 \\
-1,6\end{array}$ & $\begin{array}{c}31,7 \\
3,0\end{array}$ & $\begin{array}{c}27,8 \\
1,4\end{array}$ & $\begin{array}{l}10,0 \\
-1,3\end{array}$ & $\begin{array}{c}14,6 \\
-, 4\end{array}$ & $\begin{array}{c}13,5 \\
-, 5\end{array}$ & $\begin{array}{c}23,5 \\
1,2\end{array}$ & 16,5 \\
\hline Centro & $\begin{array}{c}25,0 \\
, 0\end{array}$ & $\begin{array}{c}14,1 \\
-3,2\end{array}$ & $\begin{array}{c}35,8 \\
2,1\end{array}$ & $\begin{array}{c}34,1 \\
1,5\end{array}$ & $\begin{array}{r}11,1 \\
-1,5\end{array}$ & $\begin{array}{l}15,0 \\
-1,7\end{array}$ & $\begin{array}{c}22,0 \\
-, 6\end{array}$ & $\begin{array}{c}37,8 \\
2,0\end{array}$ & $\begin{array}{c}35,3 \\
1,5\end{array}$ & 25,2 \\
\hline $\begin{array}{l}\text { Centro- } \\
\text { direita }\end{array}$ & $\begin{array}{c}25,0 \\
-, 4\end{array}$ & $\begin{array}{c}47,1 \\
3,0 \\
\end{array}$ & $\begin{array}{l}26,4 \\
-1,6\end{array}$ & $\begin{array}{l}24,4 \\
-1,7\end{array}$ & $\begin{array}{c}50,0 \\
1,4 \\
\end{array}$ & $\begin{array}{c}40,0 \\
, 7\end{array}$ & $\begin{array}{l}24,4 \\
-1,6\end{array}$ & $\begin{array}{c}32,4 \\
-, 4\end{array}$ & $\begin{array}{c}32,4 \\
-, 4 \\
\end{array}$ & 35,2 \\
\hline Direita & $\begin{array}{c}25,0 \\
, 8\end{array}$ & $\begin{array}{c}17,6 \\
2,2\end{array}$ & $\begin{array}{r}7,5 \\
-1,2\end{array}$ & $\begin{array}{r}4,9 \\
-1,6\end{array}$ & $\begin{array}{l}5,6 \\
-, 9\end{array}$ & $\begin{array}{c}25,0 \\
2,8\end{array}$ & $\begin{array}{c}14,6 \\
, 6\end{array}$ & $\begin{array}{c}5,4 \\
-1,4 \\
\end{array}$ & $\begin{array}{r}5,9 \\
-1,2 \\
\end{array}$ & 12,1 \\
\hline \multirow[t]{2}{*}{ Total \% (N) } & $\begin{array}{c}100,0 \\
(4)\end{array}$ & $\begin{array}{c}100,0 \\
(85)\end{array}$ & $\begin{array}{c}100,0 \\
(53)\end{array}$ & $\begin{array}{c}100,0 \\
(41)\end{array}$ & $\begin{array}{c}100,0 \\
(18)\end{array}$ & $\begin{array}{c}100,0 \\
(40)\end{array}$ & $\begin{array}{c}100,0 \\
(41)\end{array}$ & $\begin{array}{c}100,0 \\
(37)\end{array}$ & $\begin{array}{c}100,0 \\
(34)\end{array}$ & $\begin{array}{c}100 \\
(188)\end{array}$ \\
\hline & \multicolumn{4}{|c|}{ Qui-quadrado observado: 34,535} & \multicolumn{5}{|c|}{ Qui-quadrado observado: 33,818} & \\
\hline
\end{tabular}

Qui-Quadrado significativo no nível de $\mathrm{P}<0,01\left(^{*}\right) ; \mathrm{P}<0,05\left(^{* *}\right)$

Fonte: Banco de Dados CESOP / Unicamp

O conjunto destas tabelas indica uma coerência interna nos dados da pesquisa quanto às associações entre direção do voto, autoclassificação ideológica e perfil socioeconômico dos entrevistados, de acordo com os estudos prévios sobre o comportamento eleitoral na capital paulista e as análises sobre as eleições de 1989. As associações são frágeis devido ao tamanho reduzido da amostra, mas sugerem, em linhas gerais, as tendências esperadas no caso de uma amostra mais representativa.

\subsection{Conteúdos substantivos associados à direita}

Partimos então para a segunda parte da análise, na qual procuramos verificar os conteúdos substantivos associados às posições no contínuo ideológico esquerda-direita, a partir da análise de variáveis que pudessem ser significativas sobre as percepções do público da cidade de São Paulo quanto a alguns temas associados à renovação da direita.

Organizamos as variáveis em quatro grupos indicadores: (1) o igualitarismo; (2) o neoliberalismo; (3) a moralidade privada; e (4) o autoritarismo. ${ }^{19}$ As variáveis incluídas em cada um dos grupos são as seguintes:

\footnotetext{
${ }^{19} \mathrm{O}$ autoritarismo, na verdade, é um tema relacionado à clivagem autoritarismo-democratização que dominou os debates no início da Nova República, portanto não se inscreve totalmente no contexto da nova direita. Mas considerando o caráter matizado da direita, incluímos duas variáveis sobre o tema.
} 
Conteúdos Ideológicos da Nova Direita no Município de São Paulo: análise de surveys

\begin{tabular}{|c|c|c|}
\hline $\begin{array}{c}\text { Grupos } \\
\text { Indicadores }\end{array}$ & Variáveis & $\begin{array}{l}\text { Pergunta do questionário (1993) } \\
\text { (Escalas tipo Likert): } \\
\end{array}$ \\
\hline \multirow[t]{2}{*}{ Igualitarismo } & Antiigualitarismo & $\begin{array}{l}\text { "O Brasil estaria bem melhor se nós nos } \\
\text { preocupássemos menos que todo mundo seja igual" }\end{array}$ \\
\hline & $\begin{array}{l}\text { Desigualdades } \\
\text { socioeconômicas }\end{array}$ & $\begin{array}{l}\text { "Se o País for rico, não importa que haja muitas } \\
\text { desigualdades econômicas e sociais" }\end{array}$ \\
\hline \multirow{3}{*}{ Neoliberalismo } & Desregulamentação & $\begin{array}{l}\text { "É preciso dar mais liberdade para as empresas } \\
\text { dispensarem os seus empregados" }\end{array}$ \\
\hline & $\begin{array}{l}\text { Oposição ao Bem-Estar } \\
\text { social }\end{array}$ & $\begin{array}{l}\text { "O governo deveria oferecer menos serviços públicos, } \\
\text { incluindo coisas como saúde e educação, para reduzir os } \\
\text { impostos" }\end{array}$ \\
\hline & Estatização & $\begin{array}{l}\text { "Para que o país cresça, o governo deveria intervir mais } \\
\text { na economia" }\end{array}$ \\
\hline \multirow[t]{3}{*}{ Moralidade } & Homossexualismo & $\begin{array}{l}\text { "Os homossexuais são pessoas que devem ser aceitas } \\
\text { como Qualquer outra" }\end{array}$ \\
\hline & Aborto & $\begin{array}{l}\text { "Deve-se permitir o aborto a toda mulher que queira fazê- } \\
\text { lo" }\end{array}$ \\
\hline & Família & "O divórcio ameaça a sobrevivência da família" \\
\hline \multirow[t]{2}{*}{ Autoritarismo } & Militarismo & $\begin{array}{l}\text { "O País funcionaria bem melhor se os militares voltassem } \\
\text { ao poder" }\end{array}$ \\
\hline & Partido único & $\begin{array}{l}\text { "O Brasil seria bem melhor se existisse só um partido } \\
\text { político" }\end{array}$ \\
\hline
\end{tabular}

A Tabela 5 sintetiza os resultados dessa análise. Observamos que em todos os grupos há pelo menos uma variável de conteúdo associada à autolocalização na escala esquerda-direita, ao voto no primeiro ou no segundo turno das eleições de 1989 e mais freqüentemente em relação às variáveis de posição social (escolaridade e renda familiar).

O grupo em que se observa o maior número de variáveis significativas é o do "igualitarismo", que apresenta frases que desvalorizam a igualdade. No grupo "neoliberalismo", a variável estatização é também significativa, em graus diferenciados, em todos os cruzamentos. Os grupos "autoritarismo" e "moralidade" apresentam dados poucos significativos, este último menos ainda que o primeiro.

Os dados das variáveis "antiigualitarismo" e "desigualdades socioeconômicas" mostram que, conforme esperado, a direita é menos igualitária do que a esquerda, porque a concordância com as frases cresceu à medida que passamos da esquerda para a direita na escala (exceto na variável "antiigualitarismo", cujo percentual mais baixo corresponde à posição ao centro e não à esquerda). Entre os entrevistados que se auto-localizaram à direita, $59,1 \%$ concordaram com a frase que desvaloriza o igualitarismo e 54,5\% 
concordaram com a que sugere indiferença às desigualdades socioeconômicas. A primeira frase foi majoritariamente aceita pelos eleitores de Fernando Collor $(59,6 \%)$ e Paulo Maluf (56,5\%); a segunda apenas pelos eleitores de Collor $(51,1 \%)$.

\section{TABELA 5}

\section{Conteúdos ideológicos}

\begin{tabular}{|c|c|c|c|c|c|c|c|c|c|c|}
\hline $\begin{array}{l}\text { \% que } \\
\text { concorda: }\end{array}$ & $\begin{array}{l}\text { Antiigua- } \\
\text { litarismo }\end{array}$ & $\begin{array}{c}\text { Desigual- } \\
\text { dades } \\
\text { socioeco- } \\
\text { nômicas }\end{array}$ & $\begin{array}{c}\text { Des- } \\
\text { regu- } \\
\text { lamen- } \\
\text { tação }\end{array}$ & $\begin{array}{c}\text { Oposi- } \\
\text { ção ao } \\
\text { bem- } \\
\text { estar } \\
\text { social }\end{array}$ & Estatização & $\begin{array}{l}\text { Milita- } \\
\text { rismo }\end{array}$ & $\begin{array}{c}\text { Partido } \\
\text { único }\end{array}$ & $\begin{array}{l}\text { Homosse- } \\
\text { xualismo }\end{array}$ & Aborto & Família \\
\hline $\begin{array}{l}\text { Auto- } \\
\text { classifi- } \\
\text { cação } \\
\end{array}$ & $\left({ }^{* * *}\right)$ & $\left({ }^{*}\right)$ & (NS) & (NS) & $\left({ }^{* *}\right)$ & (NS) & $\left({ }^{* *}\right)$ & $\left({ }^{* * *}\right)$ & (NS) & (NS) \\
\hline Esquerda & 30,0 & 15,8 & 10,0 & 25,0 & 80,0 & 35,0 & 45,0 & 85,0 & 36,8 & 35,0 \\
\hline $\begin{array}{l}\text { Centro- } \\
\text { esquerda }\end{array}$ & 36,7 & 23,3 & 19,4 & 29,0 & 50,0 & 22,6 & 30,0 & 80,6 & 53,3 & 43,3 \\
\hline Centro & 25,5 & 24,4 & 26,1 & 19,1 & 54,2 & 23,4 & 31,9 & 87,2 & 34,0 & 46,8 \\
\hline $\begin{array}{l}\text { Centro- } \\
\text { direita }\end{array}$ & 51,5 & 47,5 & 21,9 & 37,9 & 76,9 & 34,8 & 48,5 & 65,2 & 35,4 & 40,9 \\
\hline Direita & 59,1 & 54,5 & 13,6 & 31,8 & 68,2 & 54,5 & 54,5 & 59,1 & 27,3 & 40,9 \\
\hline$\frac{\text { Voto no }}{1^{\circ} \text { turno }}$ & ("**) & 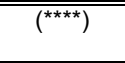 & ("***) & (NS) & ("**) & ("**) & (NS) & ("NS) & 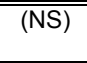 & (NS) \\
\hline F. Collor & 59,6 & 51,1 & 31,9 & 31,9 & 76,6 & 43,8 & 47,9 & 74,5 & 25,5 & 52,1 \\
\hline L. Lula & 27,6 & 27,6 & 13,8 & 27,6 & 75,9 & 13,8 & 32,1 & 75,9 & 40,7 & 28,6 \\
\hline M. Covas & 29,2 & 31,8 & 16,7 & 12,5 & 41,7 & 33,3 & 37,5 & 87,5 & 54,2 & 50,0 \\
\hline P. Maluf & 56,5 & 33,3 & 43,5 & 30,4 & 56,5 & 56,5 & 43,5 & 65,2 & 43,5 & 43,5 \\
\hline$\frac{\text { Voto no }}{1^{\circ} \text { turno }}$ & ("**) & 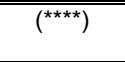 & ("**) & (" & ("**) & ("**) & (NS) & (NS) & $\begin{array}{l}\text { (NS) } \\
\end{array}$ & 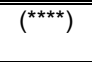 \\
\hline Direita & 55,3 & 43,1 & 36,0 & 32,9 & 67,1 & 44,7 & 43,4 & 72,0 & 34,7 & 47,4 \\
\hline Centro & 32,1 & 32,1 & 17,9 & 10,3 & 39,3 & 28,6 & 35,7 & 86,2 & 53,6 & 42,9 \\
\hline Esquerda & 28,1 & 25,0 & 12,5 & 28,1 & 75,0 & 15,6 & 31,3 & 78,1 & 40,0 & 28,1 \\
\hline$\frac{\text { Voto no }}{2^{\circ} \text { turno }}$ & ("**) & ("**) & (NS) & (NS) & ("****) & ("**) & (NS) & ("****) & 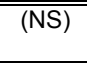 & 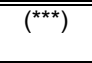 \\
\hline Collor & 48,9 & 46,4 & 25,6 & 33,3 & 65,9 & 38,9 & 41,1 & 71,4 & 36,0 & 47,8 \\
\hline Lula & 28,3 & 28,3 & 17,0 & 22,6 & 64,2 & 22,6 & 35,8 & 81,1 & 45,3 & 30,2 \\
\hline $\begin{array}{l}\text { Escolari- } \\
\text { dade }\end{array}$ & ("(***) & $\overline{\left({ }^{*}\right)}$ & $\overline{\left({ }^{* * * * *}\right)}$ & $\overline{(\overline{(* * * *})}$ & $\overline{\left({ }^{*}\right)}$ & $\left({ }^{(*)}\right.$ & $\left(\overline{(*}^{*}\right)$ & (NS) & $\overline{\left({ }^{*}\right)}$ & ("***) \\
\hline$\overline{1^{\circ} \text { grau: }}$ & 46,8 & 50,0 & 18,3 & 36,2 & 75,5 & 40,4 & 48,9 & 69,5 & 24,2 & 50,0 \\
\hline $2^{\circ}$ grau: & 41,1 & 25,5 & 16,7 & 23,6 & 65,5 & 29,1 & 50,0 & 76,4 & 46,3 & 34,5 \\
\hline Superior: & 24,4 & 15,6 & 31,1 & 22,2 & 44,4 & 15,6 & 13,3 & 84,4 & 57,8 & 31,1 \\
\hline $\begin{array}{l}\text { Renda } \\
\text { familiar }\end{array}$ & $\overline{\left({ }^{* * * *}\right)}$ & $\left(\right.$ (*) $^{*}$ & $\overline{\left({ }^{* *}\right)}$ & $\overline{\left({ }^{* * * * *}\right)}$ & $\left(\right.$ (*) $^{*}$ & 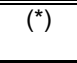 & $\overline{\left({ }^{(* *}\right)}$ & (NS) & $(\overline{(* *)}$ & (NS) \\
\hline $\begin{array}{l}\text { Até } 5 \\
\text { S.M. }\end{array}$ & 46,8 & 50,0 & 20,0 & 26,2 & 77,0 & 45,2 & 54,8 & 70,5 & 23,0 & 43,5 \\
\hline $\begin{array}{l}+5 \text { a } 10 \\
\text { S.M. }\end{array}$ & 31,8 & 23,8 & 7,0 & 34,1 & 70,5 & 34,1 & 36,4 & 75,0 & 34,9 & 40,9 \\
\hline+10 S.M. & 39,5 & 28,9 & 31,6 & 25,3 & 53,9 & 18,7 & 32,9 & 81,3 & 52,0 & 36,8 \\
\hline$\frac{\overline{T O T A L}}{(\mathrm{~N}=195)}$ & 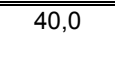 & 32,7 & 21,3 & 29,5 & "65,3 & 31,6 & 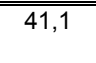 & 74,7 & $\begin{array}{l}37,8 \\
\end{array}$ & 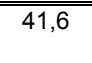 \\
\hline
\end{tabular}

Valor de Qui-quadrado observado significativo ao nível de $\mathrm{P}<0,01\left(^{*}\right) ; \mathrm{P}<0,05\left(^{(\star *}\right) ; \mathrm{P}<0,10\left(^{(\star \star}\right) ; \mathrm{P}<0,20\left(^{(* \star *}\right)$ ; P > 0,20 - não significativo (NS)

Fonte: Banco de Dados CESOP / Unicamp 
Porém é instigante que em um país marcado por tantas desigualdades sociais sejam justamente os entrevistados de posição social mais baixa os que mais concordaram com o antiigualitarismo e com as desigualdades socioeconômicas. Mas observamos que na variável "antiigualiarismo" o menor índice de concordância foi observado entre os entrevistados com renda intermediária, ascendendo, um pouco, novamente na faixa mais alta. Vimos anteriormente, na Tabela 3, que nas faixas de renda familiar mais altas havia um ligeiro incremento no voto em candidatos de direita. Diante disso, resolvemos investigar como se distribuíam as opiniões favoráveis ao antiigualitarismo de acordo com o voto e a renda familiar do entrevistado.

A Tabela 6, conseqüência do cruzamento de três variáveis, resulta em um número muito pequeno de entrevistados por células (a base de cálculo dos percentuais é o valor que aparece entre parênteses), tornando-a pouco significativa. Porém, os dados, mesmo que limitados, sugerem que quando o entrevistado votou em algum candidato à direita em 1989 , as opiniões contrárias ao igualitarismo se distribuíram com mais freqüência tanto nas faixas de renda familiar mais baixa quanto no topo, sendo o mesmo válido para os que votaram em Fernando Collor ou em Paulo Maluf. Portanto, a postura antiigualitária, predominante no público mais pobre, ressurgiu nas camadas mais ricas. No entanto, permanece a dúvida sobre o sentido do antiigualitarismo entre as camadas mais pobres, porque os dados de que dispomos não são esclarecedores.

\section{TABELA 6}

Voto no $1^{\circ}$ turno das eleições de 1989 por renda familiar

\% de concordância com a frase antiigualitária

\begin{tabular}{|c|c|c|c|c|c|}
\hline \multirow[b]{2}{*}{ Voto no $1^{\circ}$ turno: } & \multicolumn{5}{|c|}{$\begin{array}{l}\text { Renda familiar } \\
\% \text { ( Base } N \text { ) }\end{array}$} \\
\hline & $\begin{array}{l}\text { Até } 2 \\
\text { s.m. }\end{array}$ & $\begin{array}{l}+ \text { de } 2 \text { a } 5 \\
\text { s.m. }\end{array}$ & $\begin{array}{l}+ \text { de } 5 \text { a } 10 \\
\text { s.m. }\end{array}$ & $\begin{array}{l}+ \text { de } 10 \text { a } \\
20 \text { s.m. }\end{array}$ & $\begin{array}{l}\text { Mais de } 20 \\
\text { s.m. }\end{array}$ \\
\hline $\begin{array}{l}\text { Votou em um candidato de direita no } 1^{\circ} \\
\text { turno }\end{array}$ & $\begin{array}{l}80,0 \\
(10)\end{array}$ & $\begin{array}{l}41,2 \\
(17)\end{array}$ & $\begin{array}{l}45,5 \\
(11)\end{array}$ & $\begin{array}{l}64,3 \\
(14)\end{array}$ & $\begin{array}{l}53,3 \\
(15)\end{array}$ \\
\hline Votou em Fernando Collor & $\begin{array}{c}83,3 \\
(6)\end{array}$ & $\begin{array}{l}42,9 \\
(14)\end{array}$ & $\begin{array}{l}42,9 \\
(7)\end{array}$ & $\begin{array}{c}62,5 \\
(8)\end{array}$ & $\begin{array}{c}80,0 \\
(5)\end{array}$ \\
\hline Votou em Paulo Maluf & $\begin{array}{c}100,0 \\
\text { (3) }\end{array}$ & $\begin{array}{c}33,3 \\
\text { (3) }\end{array}$ & $\begin{array}{c}33,3 \\
\text { (3) }\end{array}$ & $\begin{array}{c}66,7 \\
(6)\end{array}$ & $\begin{array}{c}57,1 \\
(7)\end{array}$ \\
\hline
\end{tabular}

Fonte: Banco de Dados CESOP / Unicamp

De volta à Tabela 5 , destacamos a variável mais significativa do grupo "neoliberalismo": a estatização. Assim como foi observado por Singer (ibid.) em relação ao Brasil, o público da cidade de São Paulo foi mais favorável ao estatismo do que o contrário (na linha Total, 65,3\% a favor de mais intervenção do governo na economia) e o público de centro se mostrou menos estatizante do que os extremos, seja considerando a auto-localização na escala esquerda-direita ou a direção do voto. Porém, ao contrário do que foi observado no país, o público mais à esquerda foi mais favorável ao estatismo do 
que o mais à direita (comparando os dois extremos, $80,0 \%$ pró-estatismo à esquerda e $68,2 \%$ à direita). Neste caso, porém, a afirmação não é válida se for considerada a direção do voto. Isso porque foram os eleitores de Mário Covas, ao centro, e de Paulo Maluf, à direita, os menos favoráveis à intervenção do estado na economia e foram os eleitores de Fernando Collor, à direita, e de Lula, à esquerda, os mais favoráveis ao estatismo.

Singer (ibid.) sugere uma explicação para o estatismo de direita, que nos dados foi associado ao voto em Fernando Collor, como sendo uma forma de reforçar a autoridade de Estado dando a conotação de Estado forte. Como veremos a seguir, a direita é muito mais autoritária do que a esquerda, o que torna a explicação plausível. De toda maneira, na variável estatismo, a clivagem mais significativa ocorre nas variáveis de posição social, pois foram os entrevistados com renda mais alta e escolaridade superior os menos estatistas, justamente as categorias que mais votaram em Covas e Maluf.

Sobre as outras duas variáveis chamamos a atenção para a valorização da desregulamentação da economia (liberdade para as empresas dispensarem empregados) entre os eleitores dos candidatos de direita (com destaque para os que votaram em Paulo Maluf) e os entrevistados com melhor posição social. A variável que avalia a oposição ao bem-estar social foi também valorizada pelos eleitores dos candidatos de direita, porém mostrou-se menos significativa nos itens escolaridade e renda familiar. Mas esta última nos pareceu uma questão de difícil avaliação, porque a frase combina uma conotação negativa (redução dos serviços públicos) com uma positiva (redução de impostos).

As variáveis do grupo das questões da moralidade privada, de maneira geral, não mostraram tendências significativas. Notamos que apenas na variável "homossexualismo" os públicos de centro e de esquerda foram mais favoráveis ao respeito à opção individual do que os de direita. A variável "aborto" somente apresentou associações significativas nas faixas de renda mais altas e escolaridade superior, mais favoráveis à liberdade da mulher decidir sobre o tema. E a variável "família" sugere que as bases do voto de esquerda relacionaram menos o divórcio como uma ameaça à família.

Finalmente as variáveis do grupo autoritarismo ("militarismo" e "partido único") foram, como esperado, mais associadas ao público de direita, o voto à direita e os entrevistados com renda familiar e escolaridade mais baixas, os públicos que geralmente mais apóiam soluções autoritárias e contra as instituições democráticas (Pierucci, 1987). 


\subsection{Discussão dos dados de 1993}

Esses dados evidenciam que uma parcela do público da cidade de São Paulo, representada nesse survey, é sensível aos temas associados à nova direita, e que as visões de mundo sobre o "igualitarismo", o "estatismo" e, em menor grau, o "autoritarismo" e a "moralidade" são relacionadas ao posicionamento na escala esquerda-direita e a direção do voto nas eleições de 1989, conforme a tendência esperada.

A pesquisa também sugere pelos menos duas clivagens desse público em relação ao seu comportamento eleitoral em 1989: uma socioeconômica, que opõe de um lado os candidatos que foram mais apoiados pelo público mais pobre (Collor e Lula, no primeiro turno) aos apoiados pelos mais ricos (Covas e Maluf), e outra de conteúdo ideológico, que às vezes reflete esta mesma clivagem socioeconômica, como na questão do "estatismo" (eleitores de Lula e de Collor mais estatistas do que os eleitores de Maluf e Covas) e às vezes inverte os pares, como o igualitarismo, que coloca o público de centro mais próximo do de esquerda (ou eleitores de Mário Covas e Lula) em oposição ao de direita.

Porém se retirarmos deste diagrama o fenômeno ocasional e imprevisível do expresidente Fernando Collor e nos atermos aos outros três tradicionais candidatos paulistas, poderemos vislumbrar uma institucionalização da identidade ideológica desse público, pois perceberemos que a direção do voto e a auto-localização na escala esquerda-direita se tornarão coerentemente associadas aos conteúdos ideológicos no sentido esperado, ou seja, o público de direita (leia-se eleitores de Paulo Maluf) menos igualitário, antiestatista, mais moralista e mais autoritário do que o de esquerda.

A posição de centro, nos nossos dados, revelou-se contraditória, pois ora pendia para as posições associadas à esquerda (nos valores), ora pendia para a direita (nas atitudes), como na divisão do voto entre os candidatos do espectro esquerda-direita.

Considerando o que foi dito acima em relação à clivagem socioeconômica do voto, a explicação sociológica parece fortalecida, pois os dados sugerem que as classes altas se unem mais em torno das candidaturas de centro e de direita do que o contrário, o centro se une à esquerda, e nos conteúdos ideológicos mais ligados à ordem econômica, como a defesa do investimento privado e da desregulamentação da economia, esses interesses se aglutinam novamente.

Isso ficou evidenciado num outro recorte que fizemos com os dados. Vimos que boa parcela do público de centro, numa situação polarizada esquerda-direita, tendeu a apoiar mais a direita, independentemente de suas visões de mundo, como ficou nítido na Tabela 1, na descrição do voto no segundo turno de 1989 , em que $74 \%$ dos eleitores de centro preferiram Collor em vez de Lula. Esta afinidade maior entre a direita e o centro do que o contrário foi observada num contexto mais recente por Singer (ibid.) a partir de dados muito mais abrangentes do que os nossos. O autor constatou uma continuidade dos alinhamentos eleitorais entre 1989 e 1994 quando Fernando Henrique Cardoso, do 
PSDB em aliança com o PFL, foi eleito presidente da República. Neste estudo, Singer constatou que o Plano Real foi um fator muito influente no voto, mas não foi o único, nas palavras do autor, "o Real cumpriu um importante papel de realinhamento dos eleitores de centro e direita em direção ao candidato que os representava." (p. 132, grifo nosso).

\section{Dados de 1995}

Os dados de interesse destacados do survey de 1995 foram organizamos em dois grupos indicadores: (1) neoliberalismo; (2) moralidade. Em cada um deles foram incluídas as seguintes variáveis:

\begin{tabular}{|c|c|c|}
\hline $\begin{array}{l}\text { Grupos } \\
\text { Indicadores }\end{array}$ & Variáveis & Pergunta do questionário (1995) \\
\hline \multirow[t]{2}{*}{ Neoliberalismo } & $\begin{array}{l}\text { Monopólio da } \\
\text { Petrobrás }\end{array}$ & 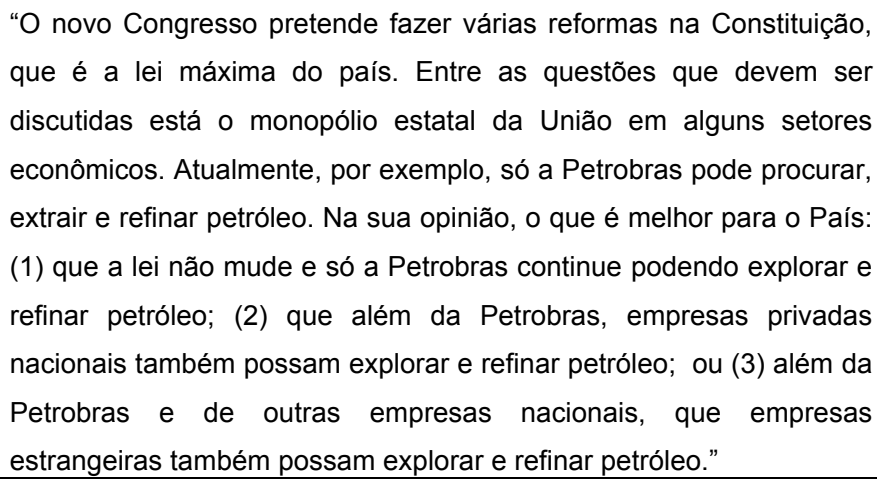 \\
\hline & $\begin{array}{l}\text { Privatização da } \\
\text { Petrobrás }\end{array}$ & $\begin{array}{l}\text { "Em relação a Petrobras, você é a favor ou contra sua privatização, } \\
\text { isto é, você é a favor ou contra que a Petrobras seja vendida para } \\
\text { acionistas privados deixando de ser empresa estatal?" }\end{array}$ \\
\hline
\end{tabular}




\begin{tabular}{|c|c|c|}
\hline Neoliberalismo & $\begin{array}{l}\text { Reforma da } \\
\text { Previdência }\end{array}$ & $\begin{array}{l}\text { "Atualmente a lei dá direito à aposentadoria por idade ou por tempo } \\
\text { de serviço. Os homens podem se aposentar aos } 65 \text { anos de idade ou } \\
\text { depois de } 35 \text { anos de serviço; as mulheres aos } 60 \text { anos ou depois de } \\
30 \text { de serviço. Na sua opinião, a aposentadoria: (1) deveria ficar } \\
\text { exatamente como está, por idade e tempo de serviço; (2) deveria ser } \\
\text { só por idade, obedecidos os limites atuais; (3) deveria ser só por } \\
\text { tempo de serviço, respeitados os prazos atuais." }\end{array}$ \\
\hline \multirow[t]{2}{*}{ Moralidade } & Aborto & $\begin{array}{l}\text { "Atualmente o aborto no Brasil só é permitido em caso de estupro ou } \\
\text { de risco de vida para a mãe. Há projetos de lei para ampliar as } \\
\text { situações em que a interrupção da gravidez seria permitida. Na sua } \\
\text { opinião, a legislação sobre o aborto: (1) deveria ficar exatamente } \\
\text { como está; (2) deveria ser permitido em mais situações especiais; (3) } \\
\text { no início da gravidez, deveria deixar de ser crime em qualquer } \\
\text { situação" }\end{array}$ \\
\hline & Homossexualismo & $\begin{array}{l}\text { "No Brasil é proibido o casamento de homossexuais, isto é, de } \\
\text { homens com homens e de mulher com mulher. Na sua opinião, o } \\
\text { casamento de homossexuais deveria continuar proibido ou deveria } \\
\text { ser permitido por lei?" }\end{array}$ \\
\hline
\end{tabular}

\subsection{Agenda neoliberal no contexto da reforma da Constituição}

Os dados coletados na cidade de São Paulo sobre o monopólio estatal em 1995 mostram que a maioria absoluta dos entrevistados $(67,7 \%)$ era favorável à abertura do setor de exploração e refino de petróleo para empresas privadas (Tabela 7) ${ }^{20}$ Apenas $25 \%$ defendiam a continuidade do monopólio da Petrobrás. Porém, na questão da privatização da estatal as opiniões se dividem, e os que eram favoráveis à privatização da Petrobrás não chegaram a formar uma maioria absoluta, mas ficaram perto: 49,1\%, enquanto $40,3 \%$ eram contra a privatização da empresa. Ou seja, encontramos mais entrevistados contrários à venda da empresa do que aqueles que defendem o monopólio.

\footnotetext{
${ }^{20}$ Para efeito de análise, duas últimas categorias foram agrupadas numa única, e a tabela confronta opiniões sobre a continuidade do monopólio estatal e sobre a quebra do monopólio com a participação de empresas privadas nacionais ou estrangeiras. Sem o agrupamento os resultados seriam: "que a lei não mude e só a Petrobrás continue podendo explorar e refinar petróleo": 25,0\%; "que além da Petrobrás, empresas privadas nacionais também possam explorar e refinar petróleo": $37,9 \%$; "além da Petrobrás e de outras empresas nacionais, que empresas estrangeiras também possam explorar e refinar petróleo": 29,7\%; "não sabe": 7,3\%
} 
TABELA 7

O monopólio da estatal na exploração / refino de petróleo e a privatização da Petrobrás

\begin{tabular}{l|c||c|c}
\hline \multicolumn{1}{c||}{$\begin{array}{c}\text { Opiniões sobre o monopólio da União no setor } \\
\text { petrolífero }\end{array}$} & $\%$ & $\begin{array}{c}\text { Opiniões sobre a } \\
\text { privatização da Petrobrás }\end{array}$ & $\%$ \\
\hline A Petrobrás continue com o monopólio & 25,0 & A favor & 49,1 \\
\hline Também empresas privadas nacionais e estrangeiras & 67,7 & Contra & 40,3 \\
\hline Não sabe & 7,3 & Indiferente & 1,7 \\
\hline \hline Total & & Não Sabe & 8,8 \\
\hline
\end{tabular}

Fonte: Banco de Dados CESOP / Unicamp

Para entender o padrão de distribuição dessas respostas, apresentamos na tabela $8^{21}$ os resultados de cruzamentos entre as opiniões sobre o monopólio estatal e a privatização da Petrobrás e as variáveis de estratificação disponíveis no questionário, a saber: escolaridade, renda familiar, faixa etária e preferência partidária no contínuo ideológico esquerda-direita. ${ }^{22}$

A Tabela 8 chama a atenção para alguns aspectos bem delineados. Em relação à variável escolaridade, observamos que o apoio ao monopólio da Petrobrás no setor de petróleo era menor do que a posição favorável à quebra do monopólio em todos os níveis de escolaridade. Observamos, também, que a quebra do monopólio teve maior apoio quanto maior o grau de instrução: de um de mínimo de 63,8\% entre os entrevistados com escolaridade até o $1^{\circ}$ grau até $89,3 \%$ entre os de nível superior. Nesse cruzamento, a associação entre estas variáveis é fortemente significativa (qui-quadrado significativo ao nível de $p<0,001)$ e todos os resíduos são também significantes, indicando que o aumento da escolarização aumenta a crítica ao monopólio no setor.

\footnotetext{
${ }^{21}$ Nestas tabelas, destacamos apenas as respostas dos entrevistados que declararam alguma opinião sobre o tema, ou seja, foram excluídos da base de dados os casos de "não sabe". Com isso, optamos por sintetizar as contingências observadas e reduzir o número de células com número de casos insignificantes para a análise. Consideramos válido optar por este procedimento, porque os casos eliminados da análise não ultrapassam a 10\% do total, as categorias chaves são preservadas ("estatismo" e "privatismo") e, apesar do crescimento do valor percentual das respostas, as proporções das diferenças entre elas se mantêm.

${ }^{22}$ Esta variável foi produzida a partir das respostas dos entrevistados à pergunta "qual é o seu partido político?". Agrupamos as opções de acordo com o seguinte critério: "Esquerda" = entrevistados que citaram PT, PDT e PSB; "Centro" = PMDB e PSDB; e "Direita" =, PFL, PPR (ex PDS, atual PPB), PTB, PRN e PL. Este critério foi o mesmo adotado para o agrupamento dos voto por candidato na pesquisa de 1993. Foram excluídas as outras respostas ("não sabe"; "não tem partido"; "citou nome"). No entanto, apenas 188 entrevistados, ou seja, 40,5\%, indicaram algum partido. Os dados da tabela são válidos, portanto, apenas para o pequeno grupo de entrevistados que preferiu algum partido, o que afetou muito a sua significância.
} 
TABELA 8

O monopólio estatal no setor petrolífero e a privatização da Petrobras segundo escolaridade, renda familiar, faixa etária e ideologia partidária

\begin{tabular}{|c|c|c|c|c|c|c|}
\hline & \multicolumn{3}{|c|}{ Monopólio estatal } & \multicolumn{3}{|c|}{ Privatização da Petrobras } \\
\hline & A favor & Contra & Total \% $(\mathrm{N})$ & A favor & Contra & Total \% (N) \\
\hline Escolaridade: & \multicolumn{3}{|c|}{$\left(^{*}\right)$} & \multicolumn{3}{|c|}{$\left({ }^{\star \star}\right)$} \\
\hline $1^{\circ} \mathrm{grau}$ & $\begin{array}{c}36,2 \\
4,7\end{array}$ & $\begin{array}{l}63,8 \\
-4,7\end{array}$ & $\begin{array}{l}100,0 \\
(235)\end{array}$ & $\begin{array}{l}47,2 \\
-3,5\end{array}$ & $\begin{array}{c}52,8 \\
3,5\end{array}$ & $\begin{array}{l}100,0 \\
(229)\end{array}$ \\
\hline $2^{\circ}$ grau & $\begin{array}{l}19,2 \\
-2,3\end{array}$ & $\begin{array}{c}80,8 \\
2,3\end{array}$ & $\begin{array}{l}100,0 \\
(120)\end{array}$ & $\begin{array}{c}63,5 \\
2,2\end{array}$ & $\begin{array}{l}36,5 \\
-2,2\end{array}$ & $\begin{array}{l}100,0 \\
(115)\end{array}$ \\
\hline \multirow[t]{2}{*}{ Superior } & $\begin{array}{l}10,7 \\
-3,5\end{array}$ & $\begin{array}{c}89,3 \\
3,5\end{array}$ & $\begin{array}{c}100,0 \\
(75)\end{array}$ & $\begin{array}{c}66,2 \\
2,1\end{array}$ & $\begin{array}{l}33,8 \\
-2,1\end{array}$ & $\begin{array}{c}100,0 \\
(71)\end{array}$ \\
\hline & \multicolumn{3}{|c|}{ Qui-quadrado observado: 23,926} & \multicolumn{3}{|c|}{ Qui-quadrado observado: 12,618} \\
\hline Renda Familiar: & \multicolumn{3}{|c|}{$\left({ }^{\prime \prime * *}\right)$} & \multicolumn{3}{|c|}{ 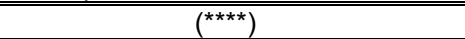 } \\
\hline Até 5 s.m. & $\begin{array}{c}30,8 \\
1,1\end{array}$ & $\begin{array}{l}69,2 \\
-1,1\end{array}$ & $\begin{array}{l}100,0 \\
(104)\end{array}$ & $\begin{array}{l}46,2 \\
-1,9\end{array}$ & $\begin{array}{c}53,8 \\
1,9\end{array}$ & $\begin{array}{l}100,0 \\
(104)\end{array}$ \\
\hline + de 5 a 10 s.m. & $\begin{array}{c}33,9 \\
2,1\end{array}$ & $\begin{array}{l}66,1 \\
-2,1\end{array}$ & $\begin{array}{l}100,0 \\
(115)\end{array}$ & $\begin{array}{c}51,9 \\
-, 6\end{array}$ & $\begin{array}{c}48,1 \\
, 6\end{array}$ & $\begin{array}{l}100,0 \\
(108)\end{array}$ \\
\hline \multirow[t]{2}{*}{ + de 10 s.m. } & $\begin{array}{l}20,1 \\
-2,8\end{array}$ & $\begin{array}{c}79,9 \\
2,8\end{array}$ & $\begin{array}{l}100,0 \\
(189)\end{array}$ & $\begin{array}{c}60,2 \\
2,2\end{array}$ & $\begin{array}{l}39,8 \\
-2,2\end{array}$ & $\begin{array}{l}100,0 \\
(181)\end{array}$ \\
\hline & \multicolumn{3}{|c|}{ Qui-Quadrado observado: 8,133 } & \multicolumn{3}{|c|}{ Qui-quadrado observado: 5,592} \\
\hline Faixa etária & \multicolumn{3}{|c|}{ (NS) } & \multicolumn{3}{|c|}{$\left({ }^{(* *}\right)$} \\
\hline 16-24 anos & $\begin{array}{c}29,8 \\
, 6 \\
\end{array}$ & $\begin{array}{c}70,2 \\
-, 6 \\
\end{array}$ & $\begin{array}{c}100,0 \\
(84)\end{array}$ & $\begin{array}{c}68,8 \\
2,8 \\
\end{array}$ & $\begin{array}{l}31,3 \\
-2,8 \\
\end{array}$ & $\begin{array}{c}100,0 \\
(80)\end{array}$ \\
\hline 25-34 anos & $\begin{array}{c}27,1 \\
, 0\end{array}$ & $\begin{array}{c}72,9 \\
, 0 \\
\end{array}$ & $\begin{array}{l}100,0 \\
(129)\end{array}$ & $\begin{array}{c}48,4 \\
-1,8 \\
\end{array}$ & $\begin{array}{c}51,6 \\
1,8 \\
\end{array}$ & $\begin{array}{l}100,0 \\
(126)\end{array}$ \\
\hline $35-44$ anos & $\begin{array}{c}26,3 \\
-, 2\end{array}$ & $\begin{array}{c}73,7 \\
, 2\end{array}$ & $\begin{array}{c}100,0 \\
(99)\end{array}$ & $\begin{array}{l}46,7 \\
-1,8\end{array}$ & $\begin{array}{c}53,3 \\
1,8\end{array}$ & $\begin{array}{c}100,0 \\
(92)\end{array}$ \\
\hline \multirow[t]{2}{*}{45 anos ou +} & $\begin{array}{c}25,4 \\
-, 4 \\
\end{array}$ & $\begin{array}{c}74,6 \\
, 4 \\
\end{array}$ & $\begin{array}{l}100,0 \\
(118)\end{array}$ & $\begin{array}{c}59,0 \\
1,0 \\
\end{array}$ & $\begin{array}{l}41,0 \\
-1,0 \\
\end{array}$ & $\begin{array}{l}100,0 \\
(117)\end{array}$ \\
\hline & \multicolumn{3}{|c|}{ Qui-Quadrado observado: ,502 } & \multicolumn{3}{|c|}{ Qui-quadrado observado: 11,600} \\
\hline Ideologia partidária & \multicolumn{3}{|c|}{ (NS) } & \multicolumn{3}{|c|}{$\left({ }^{* \star *}\right)$} \\
\hline Esquerda & $\begin{array}{c}24,7 \\
, 1 \\
\end{array}$ & $\begin{array}{c}75,3 \\
-, 1 \\
\end{array}$ & $\begin{array}{c}100,0 \\
(81)\end{array}$ & $\begin{array}{c}58,2 \\
, 0 \\
\end{array}$ & $\begin{array}{c}41,8 \\
, 0 \\
\end{array}$ & $\begin{array}{c}100,0 \\
(79)\end{array}$ \\
\hline Centro & $\begin{array}{c}27,3 \\
, 8 \\
\end{array}$ & $\begin{array}{c}72,7 \\
-, 8 \\
\end{array}$ & $\begin{array}{c}100,0 \\
(77)\end{array}$ & $\begin{array}{l}51,9 \\
-1,5 \\
\end{array}$ & $\begin{array}{c}48,1 \\
1,5 \\
\end{array}$ & $\begin{array}{c}100,0 \\
(77)\end{array}$ \\
\hline Direita & $\begin{array}{l}13,0 \\
-1,3 \\
\end{array}$ & $\begin{array}{c}87,0 \\
1,3 \\
\end{array}$ & $\begin{array}{c}100,0 \\
(23)\end{array}$ & $\begin{array}{c}81,8 \\
2,4 \\
\end{array}$ & $\begin{array}{l}18,2 \\
-2,4 \\
\end{array}$ & $\begin{array}{c}100,0 \\
(22)\end{array}$ \\
\hline
\end{tabular}

$\left({ }^{*}\right) \mathrm{P}<0,00 ;\left({ }^{* *}\right) \mathrm{P}<0,01 ;\left({ }^{* * *}\right) \mathrm{P}<0,05 ;\left(^{* * *}\right) \mathrm{P}<0,10 ;$ (NS) $\mathrm{P}>0,10$ - Não significativo

Fonte: Banco de Dados CESOP/ Unicamp 
Na seqüência, observamos que este mesmo padrão de distribuição de respostas se repetiu em relação à privatização da Petrobrás, ou seja, o aumento do apoio à privatização cresceu com a escolarização. Porém, não foi observada uma unanimidade sobre a questão da privatização entre todos os níveis de escolarização. A maioria dos entrevistados com até $01^{\circ}$ grau eram contrários à privatização da Petrobrás, tendência inversa à observada entre as outras categorias da tabela. Os valores dos resíduos ajustados são todos significativos e são maiores (em números absolutos) entre os de escolarização inferior, os que mais se diferenciam dos demais.

No cruzamento com a variável renda familiar, obtemos uma associação mais fraca do que a anterior mas ainda bastante significativa na questão do monopólio estatal (quiquadrado significativo ao nível de $p<0,05$ ). Aqui também o apoio à quebra do monopólio estatal manteve o padrão majoritário em todas as faixas de renda familiar, sendo maior ainda entre os entrevistados mais ricos. Com relação à venda da estatal, o cruzamento com a renda familiar mostra que as tendências observadas anteriormente se repetem, ou seja, que os entrevistados com menor renda familiar eram majoritariamente contrários à venda da Estatal e que quanto maior a renda familiar maior o apoio à privatização da Petrobrás.

As variáveis faixa etária e ideologia partidária somente mostraram associações significativas na questão da privatização da Petrobrás. No primeiro caso, os mais jovens (16-24 anos) eram mais favoráveis à privatização do que todos os demais. No outro, os dados corroboram com a hipótese da tendência antiestatista do público de direita ou, neste caso, identificado com os partidos de direita: os entrevistados à direita apoiavam majoritariamente à privatização. $O$ valor de qui-quadrado observado $(p<0,05)$ permite rejeitar a hipótese de que as variáveis sejam independentes, mas os valores desta associação se mostram relevantes apenas na categoria ideológica à direita, na qual o índice de entrevistados a favor da privatização ultrapassavam em mais de $20 \%$ o valor observado na tabela total.

Dentre os componentes da crise fiscal do Estado, destacamos as opiniões sobre a proposta de reforma da Previdência. Nesta pesquisa, o público foi questionado sobre a continuidade do sistema de previdência social em relação à aposentadoria, ou seja, à manutenção do sistema de cálculo da aposentadoria por tempo de serviço e por idade (que afeta a maior parte dos trabalhadores assalariados) vis-à-vis a reforma, ou seja, o limite calculado apenas por idade. Na Tabela 9, verificamos que a opinião majoritária $(74,8 \%)$ era pelo apoio à reforma proposta enquanto a posição pela manutenção do sistema foi defendido por cerca de um quarto dos entrevistados. 


\section{TABELA 9}

A reforma da Previdência Social: sistema de aposentadorias

\begin{tabular}{l|c}
\hline \multicolumn{1}{c|}{ Opiniões: } & $\%$ \\
\hline Deveria ficar exatamente como está, por idade e por tempo de serviço & 24,6 \\
\hline Deveria ser só por idade, obedecidos os limites atuais & 74,8 \\
\hline Deveria ser só por tempo de serviço, respeitando os prazos atuais & 0,2 \\
\hline Outras respostas & 0,4 \\
\hline \hline $\begin{array}{l}\text { Total }(\mathrm{N}) \\
\text { Fonte: Banco de Dados CESOP / Unicamp }\end{array}$ & 100,0 \\
\end{tabular}

Fonte: Banco de Dados CESOP / Unicamp

Nesta questão, poucas diferenças foram observadas entre os subgrupos amostrados. Apenas os cruzamentos com renda familiar e faixa etária apontam para associações significativas que passamos a destacar.

A Tabela 10 indica que, apesar de todos os grupos de renda familiar terem se colocado majoritariamente favoráveis à reforma da previdência, o público mais pobre foi um pouco menos favorável à mudança do sistema de aposentadoria. O cruzamento com a variável faixa etária mostrou duas categorias significativas: entre os mais jovens, de 16 a 24 anos, e os entrevistados com idade compreendida na faixa entre 35 e 44 anos. No grupo mais jovem, apesar da maioria ter se manifestado favoravelmente à reforma, foi observado o maior agrupamento de pessoas contrárias à mudança do atual sistema $(36,4 \%)$. Na faixa de 35 a 44 anos, encontramos os entrevistados mais favoráveis à reforma da previdência ( $88 \%)$. 
TABELA 10

A reforma da Previdência segundo escolaridade, renda familiar, faixa etária e ideologia partidária

\begin{tabular}{|c|c|c|c|}
\hline & \multicolumn{3}{|c|}{ Reforma da Previdência } \\
\hline & $\begin{array}{c}\text { A favor } \\
\text { (só por idade) }\end{array}$ & $\begin{array}{c}\text { Contra } \\
\text { (Ficar como está) }\end{array}$ & Total \% (N) \\
\hline Escolaridade: & \multicolumn{3}{|c|}{ (NS) } \\
\hline $1^{\circ} \mathrm{grau}$ & $\begin{array}{l}74,8 \\
-, 3 \\
\end{array}$ & $\begin{array}{c}25,2 \\
, 3\end{array}$ & $\begin{array}{l}100,0 \\
(262)\end{array}$ \\
\hline $2^{\circ}$ grau & $\begin{array}{c}72,6 \\
-, 8\end{array}$ & $\begin{array}{c}27,4 \\
, 8\end{array}$ & $\begin{array}{l}100,0 \\
(124)\end{array}$ \\
\hline Superior & $\begin{array}{c}81,3 \\
1,3 \\
\end{array}$ & $\begin{array}{l}18,7 \\
-1,3 \\
\end{array}$ & $\begin{array}{c}100,0 \\
(75)\end{array}$ \\
\hline & \multicolumn{3}{|c|}{ Qui-quadrado observado: 1,993} \\
\hline Renda Familiar: & \multicolumn{3}{|c|}{ 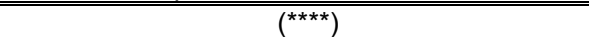 } \\
\hline Até 5 s.m. & $\begin{array}{l}69,2 \\
-2,0\end{array}$ & $\begin{array}{c}30,8 \\
2,0\end{array}$ & $\begin{array}{l}100,0 \\
(120)\end{array}$ \\
\hline+ de 5 a 10 s.m. & $\begin{array}{c}81,1 \\
1,7\end{array}$ & $\begin{array}{l}18,9 \\
-1,7\end{array}$ & $\begin{array}{l}100,0 \\
(122)\end{array}$ \\
\hline + de 10 s.m. & $\begin{array}{c}76,3 \\
, 3 \\
\end{array}$ & $\begin{array}{c}23,7 \\
-, 3 \\
\end{array}$ & $\begin{array}{l}100,0 \\
(194)\end{array}$ \\
\hline & \multicolumn{3}{|c|}{ Qui-quadrado observado: 4,788} \\
\hline Faixa etária & \multicolumn{3}{|c|}{$\left({ }^{*}\right)$} \\
\hline 16-24 anos & $\begin{array}{l}63,6 \\
-2,8 \\
\end{array}$ & $\begin{array}{c}36,4 \\
2,8 \\
\end{array}$ & $\begin{array}{l}100,0 \\
(88)\end{array}$ \\
\hline $25-34$ anos & $\begin{array}{c}76,3 \\
-, 3\end{array}$ & $\begin{array}{c}23,7 \\
-, 3\end{array}$ & $\begin{array}{l}100,0 \\
(135)\end{array}$ \\
\hline $35-44$ anos & $\begin{array}{l}88,0 \\
-3,5\end{array}$ & $\begin{array}{l}12,0 \\
-3,5\end{array}$ & $\begin{array}{l}100,0 \\
(108)\end{array}$ \\
\hline 45 anos ou + & $\begin{array}{c}71,5 \\
1,2\end{array}$ & $\begin{array}{c}28,5 \\
1,2\end{array}$ & $\begin{array}{l}100,0 \\
(130)\end{array}$ \\
\hline & \multicolumn{3}{|c|}{ Qui-quadrado observado: 16,795} \\
\hline Ideologia partidária & \multicolumn{3}{|c|}{ (NS) } \\
\hline Esquerda & $\begin{array}{l}74,4 \\
-, 6\end{array}$ & $\begin{array}{c}25,6 \\
, 6\end{array}$ & $\begin{array}{c}100,0 \\
(82)\end{array}$ \\
\hline Centro & $\begin{array}{l}73,2 \\
-, 3 \\
\end{array}$ & $\begin{array}{c}26,8 \\
, 3\end{array}$ & $\begin{array}{c}100,0 \\
(82)\end{array}$ \\
\hline Direita & $\begin{array}{c}60,9 \\
1,3\end{array}$ & $\begin{array}{l}39,1 \\
-1,3\end{array}$ & $\begin{array}{l}100,0 \\
(23)\end{array}$ \\
\hline & \multicolumn{3}{|c|}{ Qui-quadrado observado: ,426 } \\
\hline
\end{tabular}

(*) $\mathrm{P}<0,00\left(^{*}\right) ;\left(^{\star *}\right) \mathrm{P}<0,01 ;\left(^{* \star *}\right) \mathrm{P}<0,05 ;\left(^{\star * \star \star}\right) \mathrm{P}<0,10$

Fonte: Banco de Dados CESOP/ Unicamp

\subsection{Debates de temas morais no contexto da reforma da Constituição}

$\mathrm{Na}$ pesquisa de 1995, destacamos duas questões sobre temas ligados à moralidade privada: o aborto e o homossexualismo. Mas veremos que, assim como foi observado em 1993, as clivagens relacionadas a estes temas são mais associadas às categorias de posição social (escolarizados e renda familiar), não tendo sido observadas associações significativas com a variável ideologia partidária.

A Tabela 11 mostra que a maioria das opiniões sobre a legislação do aborto foi pela manutenção da atual lei que permite o aborto em casos de estupro ou risco de vida 
da mãe (46,6\%). Não deixa de ser relevante que quase um terço dos entrevistados opinaram favoravelmente à ampliação dos casos em que o aborto deveria ser permitido $(28,6 \%)$ e também o percentual de entrevistados que apoiaram a idéia de descriminalização total do aborto $(23,1 \%)$. Como o enunciado da questão não dicotomiza os entrevistados entre "a favor" ou "contra" o aborto e sim gradua as situações em que o aborto deveria ser permitido, podemos considerar que a soma das posições favoráveis à ampliação das situações possíveis de aborto e pela descriminalização da prática indica um elevado grau de liberalidade entre os entrevistados $(51,7 \%)$. De outro lado, teríamos os entrevistados contrários à ampliação das possibilidades de aborto, os que opinaram pela manutenção da lei atual $(46,6 \%)$, dentre os quais, provavelmente, estariam as pessoas contrárias a essa prática em qualquer situação. Temos, portanto, uma situação hipotética em que o grupo de entrevistados praticamente se divide ao meio sobre a questão. É um quadro muito diferente do observado na pesquisa de 1993. Apesar de perguntas diferentes e das amostras muito díspares, naquela pesquisa apenas $38 \%$ dos entrevistados concordavam com a liberdade da mulher decidir sobre o tema.

\section{TABELA 11}

A legislação sobre o aborto

\begin{tabular}{l|c}
\hline \multicolumn{1}{c|}{ Opiniões: } & $\%$ \\
\hline Deve continuar como está & 46,6 \\
\hline Deve ser permitido em mais situações especiais & 28,6 \\
\hline No início da gravidez, deixa de ser crime em qualquer situação & 23,1 \\
\hline Outras respostas & 0,2 \\
\hline Não sabe & 1,5 \\
\hline \hline Total & 100,0 \\
& $(464)$ \\
\hline
\end{tabular}

Fonte: Banco de Dados CESOP / Unicamp

Nos cruzamentos apresentados na tabela 12, mantemos as três categorias de respostas e desconsideramos as "outras respostas" que somam menos de $2 \%$. Podemos observar resultados significativos somente nos cruzamentos com as variáveis "escolaridade" e "renda familiar". Estas variáveis são, em geral, estreitamente ligadas e normalmente apontam na mesma direção, ou seja, com a primeira aumentando à medida que cresce a segunda.

No cruzamento com a variável escolaridade, notamos que foram os entrevistados com escolaridade mais baixa os mais favoráveis à manutenção dos limites previstos na legislação sobre o aborto $(53,4 \%)$, com o incremento da escolaridade aumentou o apoio à possibilidade de ampliação dos casos em que o aborto deveria ser permitido. O maior índice, $45,9 \%$, foi observado entre os entrevistados com escolarização superior, valor bem acima do conjunto da amostra. A última categoria da tabela ("que o aborto deixe de ser crime em qualquer situação") indica associação significativa somente nos casos dos 
entrevistados com escolaridade intermediária, que foram os menos favoráveis à descriminalização.

O cruzamento com a renda familiar segue o mesmo padrão anterior: os entrevistados com renda mais baixa foram menos favoráveis a mudanças na atual legislação $(64,7 \%)$. Noutro sentido, à medida que aumentou a renda cresceu o apoio à ampliação do aborto legal. O menor valor foi observado entre os entrevistados com renda familiar de até 5 s.m.(17,2\%) e o maior na faixa de renda acima de 10 s.m. $(37,5 \%)$.

\section{TABELA 12}

A legislação do aborto segundo escolaridade, renda familiar, faixa etária e ideologia partidária

\begin{tabular}{|c|c|c|c|c|}
\hline & \multicolumn{3}{|c|}{ Legislação do aborto } & \multirow[b]{2}{*}{ Total \% $(\mathrm{N})$} \\
\hline & $\begin{array}{c}\text { Continuar como } \\
\text { está }\end{array}$ & $\begin{array}{c}\text { Permitido em mais } \\
\text { situações }\end{array}$ & $\begin{array}{c}\text { Deixe de ser } \\
\text { crime }\end{array}$ & \\
\hline Escolaridade: & \multicolumn{4}{|c|}{$\left({ }^{*}\right)$} \\
\hline $1^{\circ}$ grau & $\begin{array}{c}53,4 \\
2,9\end{array}$ & $\begin{array}{l}20,3 \\
-4,6\end{array}$ & $\begin{array}{c}26,3 \\
1,6\end{array}$ & $\begin{array}{l}100,0 \\
(251)\end{array}$ \\
\hline $2^{\circ}$ grau & $\begin{array}{l}46,7 \\
-, 2 \\
\end{array}$ & $\begin{array}{l}36,9 \\
2,2 \\
\end{array}$ & $\begin{array}{l}16,4 \\
-2,2 \\
\end{array}$ & $\begin{array}{l}100,0 \\
(122)\end{array}$ \\
\hline Superior & $\begin{array}{l}28,4 \\
-3,6 \\
\end{array}$ & $\begin{array}{c}45,9 \\
3,5\end{array}$ & $\begin{array}{l}25,7 \\
, 5\end{array}$ & $\begin{array}{c}100,0 \\
(74)\end{array}$ \\
\hline & \multicolumn{4}{|c|}{ Qui-quadrado observado: 27,579} \\
\hline Renda Familiar: & \multicolumn{4}{|c|}{$\left({ }^{*}\right)$} \\
\hline Até 5 s.m. & $\begin{array}{c}64,7 \\
4,1 \\
\end{array}$ & $\begin{array}{l}17,2 \\
-3,3 \\
\end{array}$ & $\begin{array}{l}18,1 \\
-1,3 \\
\end{array}$ & $\begin{array}{l}100,0 \\
(116) \\
\end{array}$ \\
\hline + de 5 a 10 s.m. & $\begin{array}{c}48,2 \\
, 0 \\
\end{array}$ & $\begin{array}{l}27,2 \\
-, 5 \\
\end{array}$ & $\begin{array}{l}24,6 \\
, 6 \\
\end{array}$ & $\begin{array}{l}100,0 \\
(114) \\
\end{array}$ \\
\hline + de 10 s.m. & $\begin{array}{l}38,5 \\
-3,7 \\
\end{array}$ & $\begin{array}{l}37,5 \\
3,4\end{array}$ & $\begin{array}{c}24,0 \\
, 7 \\
\end{array}$ & $\begin{array}{l}100,0 \\
(192)\end{array}$ \\
\hline & \multicolumn{4}{|c|}{ Qui-quadrado observado: 21,980} \\
\hline Faixa etária & \multicolumn{4}{|c|}{ (NS) } \\
\hline 16-24 anos & $\begin{array}{l}45,3 \\
-, 4 \\
\end{array}$ & $\begin{array}{c}34,9 \\
1,3\end{array}$ & $\begin{array}{l}19,8 \\
-, 9 \\
\end{array}$ & $\begin{array}{c}100,0 \\
(86)\end{array}$ \\
\hline 25-34 anos & $\begin{array}{l}45,9 \\
-, 4 \\
\end{array}$ & $\begin{array}{c}30,4 \\
, 4 \\
\end{array}$ & $\begin{array}{c}23,7 \\
, 1 \\
\end{array}$ & $\begin{array}{l}100,0 \\
(135)\end{array}$ \\
\hline $35-44$ anos & $\begin{array}{c}52,4 \\
1,2 \\
\end{array}$ & $\begin{array}{l}25,2 \\
-1,0 \\
\end{array}$ & $\begin{array}{l}22,3 \\
-, 2 \\
\end{array}$ & $\begin{array}{l}100,0 \\
(103)\end{array}$ \\
\hline 45 anos ou + & $\begin{array}{l}46,3 \\
-, 3 \\
\end{array}$ & $\begin{array}{l}26,8 \\
-, 6 \\
\end{array}$ & $\begin{array}{c}26,8 \\
1,0 \\
\end{array}$ & $\begin{array}{l}100,0 \\
(123)\end{array}$ \\
\hline & \multicolumn{4}{|c|}{ Qui-quadrado observado:, 720} \\
\hline Ideologia partidária & \multicolumn{4}{|c|}{ (NS) } \\
\hline Esquerda & $\begin{array}{c}45,0 \\
, 2 \\
\end{array}$ & $\begin{array}{l}31,3 \\
, 3\end{array}$ & $\begin{array}{l}23,8 \\
-, 5 \\
\end{array}$ & $\begin{array}{c}100,0 \\
(88)\end{array}$ \\
\hline Centro & $\begin{array}{c}44,0 \\
, 0\end{array}$ & $\begin{array}{l}25,9 \\
-1,1 \\
\end{array}$ & $\begin{array}{c}29,6 \\
1,1 \\
\end{array}$ & $\begin{array}{c}100,0 \\
(81)\end{array}$ \\
\hline Direita & $\begin{array}{l}40,9 \\
-, 3\end{array}$ & $\begin{array}{l}40,9 \\
1,2 \\
\end{array}$ & $\begin{array}{l}18,2 \\
-, 9 \\
\end{array}$ & $\begin{array}{c}100,0 \\
(22)\end{array}$ \\
\hline
\end{tabular}

$\left(^{*}\right) \mathrm{P}<0,00\left(^{*}\right) ;\left(^{* *}\right) \mathrm{P}<0,01 ;\left(^{* * *}\right) \mathrm{P}<0,05 ;\left(^{(* \star *}\right) \mathrm{P}<0,10$

Fonte: Banco de Dados CESOP/ Unicamp 
A tabela 13 mostra as opiniões sobre a união civil entre homossexuais, que no questionário é simplificado como "casamento entre homossexuais". Os resultados apresentados indicam que uma lei neste sentido reunia uma grande rejeição, traduzida pela rejeição de quase $70 \%$ dos entrevistados.

TABELA 13

A união civil entre homossexuais

\begin{tabular}{l|c}
\hline \multicolumn{1}{c|}{ Opiniões: } & $\%$ \\
\hline Deve continuar proibido & 68,9 \\
\hline Deve ser permitido por lei & 28,9 \\
\hline Não sabe & 2,2 \\
\hline \hline Total & 100,0 \\
& $(464)$ \\
\hline
\end{tabular}

Fonte: Banco de Dados CESOP / Unicamp

Os cruzamentos sobre essa questão mostram que o aumento da escolaridade e da renda familiar afetam positivamente a aceitação dessa lei e o aumento da idade e a posição política de direita influem negativamente (apesar do cruzamento com a variável ideologia não ser significativo, por um critério mais rígido). As maiores rejeições à lei do casamento entre homossexuais foram observadas entre os entrevistados com escolarização até o $1^{\circ}$ grau $(77,9 \%)$, renda familiar mais baixa (84,9\%), idade acima de 45 anos $(80 \%)$ e simpatizantes dos partidos de direita $(78,3 \%)$. 
TABELA 14

A união civil entre homossexuais segundo escolaridade

\begin{tabular}{|c|c|c|c|}
\hline & \multicolumn{3}{|c|}{ União civil entre homossexuais } \\
\hline & A favor & Contra & Total \% (N) \\
\hline Escolaridade: & \multicolumn{3}{|c|}{$\left({ }^{*}\right)$} \\
\hline $1^{\circ}$ grau & $\begin{array}{l}22,1 \\
-4,1\end{array}$ & $\begin{array}{c}77,9 \\
4,1\end{array}$ & $\begin{array}{l}100,0 \\
(262)\end{array}$ \\
\hline $2^{\circ}$ grau & $\begin{array}{c}36,4 \\
1,9\end{array}$ & $\begin{array}{l}63,6 \\
-1,9\end{array}$ & $\begin{array}{l}100,0 \\
(118)\end{array}$ \\
\hline Superior & $\begin{array}{c}45,2 \\
3,2\end{array}$ & $\begin{array}{l}54,8 \\
-3,2\end{array}$ & $\begin{array}{c}100,0 \\
(73)\end{array}$ \\
\hline & \multicolumn{3}{|c|}{ Qui-quadrado observado: 18,190} \\
\hline Renda Familiar: & \multicolumn{3}{|c|}{$\left({ }^{*}\right)$} \\
\hline Até $5 \mathrm{~s} . \mathrm{m}$. & $\begin{array}{l}15,1 \\
-4,3\end{array}$ & $\begin{array}{c}84,9 \\
4,3\end{array}$ & $\begin{array}{l}100,0 \\
(119)\end{array}$ \\
\hline+ de 5 a 10 s.m. & $\begin{array}{c}35,3 \\
1,3\end{array}$ & $\begin{array}{l}64,7 \\
-1,3 \\
\end{array}$ & $\begin{array}{l}100,0 \\
(119)\end{array}$ \\
\hline + de 10 s.m. & $\begin{array}{c}37,6 \\
2,7 \\
\end{array}$ & $\begin{array}{l}62,4 \\
-2,7 \\
\end{array}$ & $\begin{array}{l}100,0 \\
(189)\end{array}$ \\
\hline & \multicolumn{3}{|c|}{ Qui-quadrado observado: 18,942} \\
\hline Faixa etária & \multicolumn{3}{|c|}{$\overline{(* \star})$} \\
\hline 16-24 anos & $\begin{array}{c}37,9 \\
1,9 \\
\end{array}$ & $\begin{array}{l}62,1 \\
-1,9 \\
\end{array}$ & $\begin{array}{c}100,0 \\
(87)\end{array}$ \\
\hline 25-34 anos & $\begin{array}{c}38,5 \\
2,7\end{array}$ & $\begin{array}{l}61,5 \\
-2,7\end{array}$ & $\begin{array}{l}100,0 \\
(135)\end{array}$ \\
\hline $35-44$ anos & $\begin{array}{l}23,1 \\
-1,7 \\
\end{array}$ & $\begin{array}{c}76,9 \\
1,7 \\
\end{array}$ & $\begin{array}{l}100,0 \\
(104)\end{array}$ \\
\hline 45 anos ou + & $\begin{array}{r}19,7 \\
-2,9 \\
\end{array}$ & $\begin{array}{c}80,3 \\
2,9 \\
\end{array}$ & $\begin{array}{l}100,0 \\
(127)\end{array}$ \\
\hline & \multicolumn{3}{|c|}{ Qui-quadrado observado: 16,172} \\
\hline Ideologia partidária & \multicolumn{3}{|c|}{ (NS) } \\
\hline Esquerda & $\begin{array}{c}38,3 \\
, 0\end{array}$ & $\begin{array}{l}61,7 \\
-1,6\end{array}$ & $\begin{array}{c}100,0 \\
(81)\end{array}$ \\
\hline Centro & $\begin{array}{c}29,1 \\
1,5\end{array}$ & $\begin{array}{c}70,9 \\
, 8\end{array}$ & $\begin{array}{c}100,0 \\
(79)\end{array}$ \\
\hline Direita & $\begin{array}{l}21,7 \\
-2,4 \\
\end{array}$ & $\begin{array}{c}78,3 \\
1,2 \\
\end{array}$ & $\begin{array}{c}100,0 \\
23\end{array}$ \\
\hline
\end{tabular}

$\left(^{*}\right) \mathrm{P}<0,00\left(^{*}\right) ;\left(^{* *}\right) \mathrm{P}<0,01 ;\left(^{* * *}\right) \mathrm{P}<0,05 ;\left(^{* * * *}\right) \mathrm{P}<0,10$

Fonte: Banco de Dados CESOP/ Unicamp 


\subsection{Discussão dos dados de 1995}

Os dados apresentados no grupo de variáveis indicadoras do neoliberalismo sugerem que na questão do estatismo o campo pareceu francamente favorável às reformas, tanto pela quebra do monopólio estatal no setor petrolífero quanto pela privatização da Petrobrás, esta última em menor grau. De maneira geral, encontramos opiniões mais favoráveis à abertura do setor e à privatização entre os entrevistados com escolaridade e renda familiar mais altas. Nestes casos, as associações se mostraram quase sempre significativas, ou seja, podemos concluir que o aumento da escolarização e da renda familiar afetaram positivamente as opiniões favoráveis. As duas outras variáveis nem sempre foram significativas. A faixa etária se mostrou relevante na questão da privatização e a variável ideologia partidária mostrou-se significativa apenas no cruzamento sobre a privatização da Petrobrás: os entrevistados que apoiaram os partidos classificados como de direita foram os mais favoráveis à privatização da empresa.

A questão da reforma da previdência convergiu para uma maioria absoluta de aprovação e os dados revelaram poucas diferenças significativas entre os subgrupos, inclusive na questão da ideologia partidária. Esse resultado sugere que o discurso oficial pela reforma da previdência foi absorvido pelo público de maneira geral. ${ }^{23}$ Parece contraditório que a maioria das pessoas possam apoiar medidas que, em tese, contrariam os interesses delas próprias. Porém, os debates públicos sobre a questão da previdência têm enfatizado muito os privilégios das aposentadorias públicas. Nossos dados não permitem avançar por esse caminho, mas fica um hipótese que esse ponto de vista sobre o problema possa ter enviesado a avaliação dos entrevistados.

Nos temas morais, os dados da pesquisa de 1995 acentuam as tendências observadas em 1993 em relação às clivagens por posição social: os entrevistados mais bem posicionados (mais escolarizados e com renda familiar maior) tenderam a ser mais liberais. Quanto à associação entre estes temas e a ideologia partidária, os dados disponíveis se mostraram menos conclusivos. ${ }^{24}$

\footnotetext{
${ }^{23}$ Esta tendência observada na cidade de São Paulo contrasta bastante com uma informação de pesquisa do início de 1992 , realizada no País. Na oportunidade, entre os eleitores questionados sobre a possibilidade de reforma do sistema de aposentadoria, apenas $34 \%$ se manifestaram a favor da mudança. Fonte: Pesquisa nacional IBOPE, de 31/01/92. Banco de dados do CESOP / Unicamp.

${ }^{24}$ A variável identidade partidária é menos efetiva que a identidade ideológica porque há um tendência de que em pesquisas quantitativas somente o público mais politizado responda a questão. Assim, na pesquisa de 1993, 98\% dos entrevistados se autolocalizaram na escala esquerda-direita, e 55\% declararam preferência partidária. Em 1995, à falta de uma pergunta sobre identificação ideológica no questionário, tivemos que basear nossa análise nos 40,5\% que responderam à questão sobre preferência partidária. Uma análise comparativa sobre a efetividade destas duas variáveis em estudos políticos-eleitorais encontra-se em Singer (1998).
} 


\section{Conclusão}

Os dados de opinião apresentados nos permitem tirar algumas conclusões a respeito das percepções do público da cidade de São Paulo sobre os conteúdos geralmente associados ao contexto da nova direita vis-a-vis o comportamento eleitoral desse público.

Em primeiro lugar, eles sugerem que o inventário dos conteúdos ideológicos e políticos associados à direita, como esperado, indica um fenômeno plural. Há uma direita mais identificada com os temas econômicos da agenda neoliberal e há outra, mais popular, conservadora nas questões morais, e autoritária na forma de ver a política. Esta clivagem de conteúdo se refletiu no comportamento eleitoral e se mostrou associada às variáveis de posição social.

Em segundo lugar, os dados coletados em 1993 indicam que o igualitarismo é um valor importante para a compreensão das posições no contínuo ideológico esquerdadireita, pois, mesmo que o público da cidade de São Paulo tenha se mostrado de maneira geral mais favorável ao igualitarismo, os entrevistados que se auto-localizarem à esquerda foram mais igualitários do que os à direita, apesar dos ao centro terem sido mais igualitários do que os à esquerda. Mas as posições do centro foram às vezes contraditórias, pois em alguns valores e atitudes o centro se aproximava da direita, como nas questões sobre a desregulamentação e a estatização, e em outras oscilava entre os extremos, como no episódio aqui destacado da transferência de voto nas eleições de 1989, quando os eleitores que votaram em candidatos do centro no primeiro turno se dividiram quase meio a meio entre os dois que passaram para o segundo turno, apesar do perfil centro-esquerda do principal candidato de centro à época, Mário Covas.

As opiniões antiigualitárias ocorreram com maior freqüência junto ao público mais pobre e menos escolarizado, justamente os mais prejudicados pelas desigualdades sociais. Este é um aspecto que os nossos dados não elucidam. Vimos, porém, que entre os públicos que votaram para presidente em 1989 nos candidatos da direita as posições antiigualitárias apareceram acima da média geral tanto na base da pirâmide quanto no topo, entre os entrevistados situados nas faixas de renda familiar mais altas. Portanto, estes dados reforçam a vinculação do antiigualitarismo com as classes altas e baixas pelo filtro ideológico.

Em terceiro lugar, o conteúdo que melhor diferencia as posições esquerda-direita, segundo os dados de que dispomos, são os temas da agenda neoliberal, medidos na pesquisa pelas questões sobre a estatização (1993) e a privatização (1995). Isto reforça a tese de que a agenda neoliberal é a principal corrente da nova direita atualmente, que aglutina todos os interesses "das direitas" no espaço público político. Considerando, porém, a direção do voto em 1989, a estatização foi associada tanto aos eleitores do candidato mais esquerdista, Lula, quanto do mais direitista, Fernando Collor. Para entender este paradoxo, valemos-nos da explicação de que a estatização para a direita 
significa o apoio à autoridade do Estado (Singer, ibid.). Isso nos pareceu muito congruente com outros dados da pesquisa (a maior associação das variáveis do autoritarismo com a direita), mas também com a própria trajetória de Collor, que se apresentou ao público como um líder salvador da pátria (Dreifuss, 1989).

Em 1995, a aprovação majoritária da possibilidade de quebra do monopólio da união e da privatização da estatal do setor petrolífero sugere que os temas econômicos da agenda neoliberal se encontravam bastante disseminados na sociedade e que, pelo menos naquele momento, as políticas públicas nessa direção tinham grande respaldo junto ao público, principalmente se um público mais rico, escolarizado, jovem e identificado com algum dos partidos de direita. Os dados indicam que o sentimento a favor do estatismo predominante nos anos 80 diminuiu sensivelmente. As opiniões se tornaram mais favoráveis à redução do papel produtivo do Estado, sinalizando que boa parcela do público embarcou no sentido para onde corre o leito do rio atualmente. ${ }^{25}$ Daí porque, mais uma vez, colhemos indícios que os temas econômicos, sobretudo o estatismo, são os grandes divisores da clivagem esquerda-direita, e o neoliberalismo pode ser considerado a principal corrente da nova direita. A evolução da opinião pública nesse sentido deve ter servido como respaldo para a aprovação da quebra do monopólio do petróleo e o endurecimento do governo no enfrentamento da greve do setor ocorrido no primeiro ano do mandato de Fernando Henrique Cardoso (Oliveira, 1995)

Em quarto lugar, a classe social foi um dos fatores mais importantes para explicar as diferentes posições ideológicas e os elementos associados a cada uma delas. Em geral, as classes mais altas (considerando a escolaridade e a renda familiar) foram mais favoráveis à maneira neoliberal de lidar com as questões econômicas, apesar de a maioria do público destes estratos se autolocalizarem ao centro na escala ideológica esquerda-direita; e os mais pobres e menos escolarizados em geral defenderam os temas conservadores da moralidade privada e as soluções fortemente autoritárias (governo militar e partido único).

Finalmente, as conclusões precedentes nos sugerem, ainda que toscamente, alguns subsídios para a compreensão do voto de direita na cidade de São Paulo. Com base nos dados de 1993, sobre o comportamento eleitoral em 1989, constatamos a "pluralidade" da direita. Há uma direita mais ideológica, mais politizada, que defende os interesses do laissez-faire, que não assume totalmente o rótulo "direita" mas que é no mínimo anti-esquerda, em geral identificada com as classes mais altas. Esta direita esteve associada ao voto em Paulo Maluf no primeiro turno. Há um direita mais populista, personalista, que mobilizada apoio pelo viés apolítico dos temas da moralidade e pelas

\footnotetext{
${ }^{25}$ Duas pesquisas realizadas em 1989, que tratam especificamente da privatização da Petrobras, corroboram para fortalecer esta tendência. Uma delas, cobrindo todo o País, encontrou apenas 16\% de opiniões favoráveis à privatização; a outra, com os públicos das cidades do Rio de Janeiro e São Paulo, encontrou um índice um pouco maior, 28\%, mas bem abaixo do índice encontrado na pesquisa que estamos analisando. Fonte: Pesquisa IBOPE (novembro de 1989) com eleitores do Brasil e pesquisa Datafolha com eleitores da cidade de São Paulo e Rio de Janeiro (18-19/10/89). Banco de dados do CESOP / Unicamp
} 
formas autoritárias de agir no espaço político, geralmente encontrando suas bases nas classes mais baixas. Esta direita esteve associada à candidatura de Fernando Collor. Ocorre que na situação extremamente polarizada do segundo turno daquela eleição, os interesses "das direitas" se uniram e a direita mais ideológica e politizada votou no candidato da direita populista, Fernando Collor. Podemos concluir, portanto, que o eleitor é sensível ao debate ideológico.

Não temos dados para avaliar estas questões em contextos mais recentes na cidade de São Paulo. Mas há informações de pesquisas que nos permitem concluir que o voto de direita na cidade de São Paulo é uma tendência que vem se institucionalizando. Lima (1995), por exemplo, analisando o fenômeno da volatilidade eleitoral na cidade entre 1985 e 1992, argumenta que, a despeito dos fatores de curto prazo, a estabilidade ideológica (o alinhamento dos blocos ideológicos) é maior do que a preferência por partidos políticos, até porque o sistema partidário é muito instável. ${ }^{26}$ Nas palavras do autor: "quando usamos critérios mais 'finos' de pesquisa, verificamos que existem certas 'permanências' que não podem ser ignoradas. O eleitorado paulistano não é homogêneo, mas composto de um conjunto de eleitores dentro da mesma unidade política. [...] Os alinhamentos verificados na década de 70 , em termos de blocos ideológicos, continuam presentes. Os candidatos conservadores encontram melhor acolhida nas áreas centrais e mais ricas da cidade..." (p. 126). O trabalho de Singer (1998), que comparou a importância da variável identidade ideológica nas eleições presidenciais de 1989 e 1994, também reforça este raciocínio. Ele verificou que entre as duas eleições houve uma certa estabilidade da identificação ideológica nas escolhas eleitorais. Em 1994, apesar do fator conjuntural que foi o plano de estabilização econômica (o Plano Real), segundo os dados de opinião pública analisados pelo autor, foi possível constatar que "a importância do real para a definição do voto foi tanto mais forte quanto mais à direita estava o eleitor" (p. 172).

Neste trabalho, com uma análise de dados secundários de opinião pública, procuramos mais levantar e construir questões do que respondê-las, dada a limitação de nossos dados. Longe de esgotar o tema, pretendemos contribuir para a compreensão do mosaico de conceitos e posições associados à nova direita e, com isso, lançar luz sobre a questão da renovação contínua da direita no Brasil e especialmente na cidade de São Paulo. Procuramos trabalhar com algumas idéias-chave e fomos tratando de esclarecê-las a partir da referência internacional, nacional e das pesquisas de que dispomos. Uma vez que lidamos com dados secundários, uma série de conclusões permaneceram em aberto, pois não temos como reconstruir as questões de acordo com as nossas hipóteses. Mas foi possível perceber tendências relevantes no público pesquisado a respeito de alguns itens associados à nova direita. Certamente os resultados não são conclusivos; indicam somente que é preciso pesquisar mais sobre a questão. A partir do esboço que traçamos,

\footnotetext{
${ }^{26}$ Sobre isto, ver em Mainwaring, et al. (op. cit.) uma análise sobre a estabilidade do bloco ideológico da direita ao nível das elites político-partidárias do país, sobretudo a partir da Nova República, a despeito da instabilidade dos partidos conservadores.
} 
abre-se uma perspectiva para que este trabalho seja ampliado, aprofundado e atualizado, sobretudo no atual contexto em que os rótulos esquerda e direita têm sido freqüentemente descartados.

\section{BIBLIOGRAFIA}

ALVES, Maria Teresa Gonzaga. (1999) Repensando a Nova Direita: subsídios para compreensão do apoio a candidatos de direita no município de São Paulo de 1988 a 1996. São Paulo, Dissertação de Mestrado, USP, 178 pp.

ANDERSON, Perry. (1995) Balanço do neoliberalismo. In Emir Sader, Pablo Gentili (org.), Pósneoliberalismo: as políticas sociais e o Estado democrático, Rio de Janeiro: Paz e Terra, p.9-23.

BOBBIO, Norberto. (1995) Direita e Esquerda: razões e significados de uma distinção política, São Paulo: Ed. Universidade Estadual Paulista.

CUEVA, Agostín. (1989) A guinada conservadora. In CUEVA, Agostín (org.) Tempos conservadores, São Paulo: Hucitec: 19-38.

DREIFUSS, René. (1989) O jogo da direita, Petrópolis: Vozes.

FUCHS, Dieter \& KLINGEMANN, Hans-Dieter.(1990) The Left-Right Schema. In JENNINGS, M. Kent, DETH, Jan W. van, BARNES, Samuel, et al., Continuities in Political Action. A Longitudinal Study of Political Orientations in Three Western Democracies, Belim e New York: Walter de Gruyter: 203-234.

GIDDENS, Anthony. (1994) Beyond Left and Right. The Future of Radical Politics, Stanford: Stanford University Press.

HABERMAS, Jüergen. (1989) Neoconservative Cultural Cristicism in the Unided States and West Germany . In The New Conservatism, Cambridge: MIT Press: 22-47.

HUNTER, Allen. (1981) Entre bastidores: ideologia y organización de la nueva derecha. Revista Mexicana de Sociologia, n. ${ }^{\circ} 43:$ 1745-1780.

IGNAZI, Piero. (1992) The silent counter-revolution. European Journal of Political Research, n²2:334.

IGNAZI, Piero \& YSMAL, Colette. (1992). New and old extreme right parties: the French Front National and the Italian Movimento Sociale. European Journal of Political Research, $n^{\circ}$ 22:101121.

JACKMAN, Robert W. \& VOLPERT, Karin, "Conditions Favouring Parties of the Extreme Right in Western Europe". The British Journal of Political Science, n. ${ }^{\circ} 26,1996:$ 501-521.

LAMOUNIER, Bolívar \& CARDOSO, Fernando Henrique. (1974) Os Partidos e as Eleições no Brasil, Rio de Janeiro: Paz e Terra. 
LAMOUNIER, Bolívar. (1989) Partidos e Utopias: O Brasil no limiar dos anos 90, São Paulo: Edições Loyola.

LAMOUNIER, Bolívar \& MUSCYNSKI, Judith. (1983) A vitória do (P)MDB. Textos IDESP, $\quad$ n. ${ }^{\circ} 2$, São Paulo: IDESP

LAMOUNIER, Bolívar \& SOUZA, Amaury. (1991) Democracia e reforma institucional no Brasil: uma cultura política em mudança. Dados, 34(3): 311-348.

LIMA, Marcelo Oliveira Coutinho de. (1995) Volatilidade eleitoral em São Paulo (1985-1992). São Paulo, Dissertação de Mestrado, USP: 148 pp.

MAINWARING, Scott, MENEGUELLO, Rachel \& POWER, Timothy (2000) Conservative Parties, Democracy and Economic Reform in Contemporary Brazil. In MIDDLEBROOK, K.(ed.) Conservative Parties, the Right and Democracy in Latin America, Johns Hopkins. 2000.

MARTINS, Leôncio. (1987) Quem é quem na Constituinte: um análise sócio-política dos partidos e deputados, São Paulo: OESP-Maltese.

MENEGUELLO, Rachel \& MARTINS ALVES, Ricardo M. (1986) Tendências Eleitorais em São Paulo (1974-1985). In LAMOUNIER, Bolívar (org.), 1985: o Voto em São Paulo, coleção História Eleitoral. vol. 1, São Paulo, IDESP.

MOISÉS, José Álvaro. (1990) Eleições, Participação e Cultura Política: Mudanças e Continuidade. Lua Nova, Revista de Cultura e Política, CEDEC, n. ${ }^{\circ} 22: 133-187$.

MOUFFE, Chantal. (1981) Democracia y nueva derecha. Revista Mexicana de Sociologia, $\mathrm{n}^{\circ} 34$ : 1829-1846.

MUSZYNSKI, Maria Judith de Brito. (1989) Os eleitores Paulistanos em 1986: a marca do oposicionismo. SADEK, Maria Tereza (org.), História Eleitoral do Brasil - Eleições/1986, São Paulo, IDESP.

NOVAIS, Carlos Alberto Marques. (1996a) O primeiro turno da eleição para prefeito de São Paulo. Novos Estudos Cebrap n 45: 3-20.

NOVAIS, Carlos Alberto Marques. (1996b) A geografia do voto em São Paulo. Novos Estudos Cebrap n 46: 3-21.

OLIVEIRA, Francisco. (1995) Neoliberalismo à brasileira. In SADER, Emir e GENTILI, Pablo (org.), Pós-neoliberalismo: as políticas sociais e o Estado democrático, Rio de Janeiro: Paz e Terra: 2428.

PIERUCCI, Antônio Flávio. (1987) As bases da nova direita. Novos Estudos Cebrap n. ${ }^{\circ} 19: 26-45$.

PIERUCCI, Antônio Flávio. (1989) A Direita mora do outro lado da cidade. Revista Brasileira de Ciências Sociais, vol. 4(10): 44-65.

PIERUCCI, Antônio Flávio \& LIMA, Marcelo Coutinho de. (1991) A Direita que flutua. Novos Estudos Cebrap, n. ${ }^{\circ}$ 29: 10-27.

PIERUCCI, Antônio Flávio \& LIMA, Marcelo Coutinho de. (1993) São Paulo 92, a vitória da direita. Novos Estudos Cebrap, n³5: 94-99. 
SADEK DE SOUZA, Maria Tereza. (1986) A trajetória de Jânio Quadros. In LAMOUNIER, Bolívar (org.), 1985: o Voto em São Paulo, coleção História Eleitoral, vol. 1, São Paulo: IDESP: 66-90.

SINGER, André. (1993) Ideologia e voto no segundo turno da eleição presidencial de 1989. São Paulo, Dissertação de Mestrado, USP, 142 p.

SINGER, André. (1998) Identificação ideológica e voto no Brasil. São Paulo, Tese de Doutorado, USP, $210 \mathrm{p}$.

SMITH, Tom W. (1992) Are Conservative Churches Growing?. Review of Religious Research, $\mathrm{n} .{ }^{\circ}$ 33: 303-322.

SOUZA, Maria do Carmo Campello. (1992) "The Contemporary Faces of the Brasilian Right: An Interpretation of Style and Substance", in CHALMERS, Douglas A., CAMPELLO DE SOUZA, Maria do Carmo and BORON, Atilio (ed.), The Right and Democracy in Latin America, New York: Praeger, 99-127.

TAGUIEFF, Pierre-André. (1990) The new cultural racism in France. Telos, n 83: 109-122.

TAGUIEFF, Pierre-André. (1993-1994) From Race to Culture: The New Right's View of Europen Identity. Telos, $\mathrm{n}^{\circ}$ 98-99(volume duplo): 99-125. 